\title{
Clonal Patterns of Cell Proliferation, Migration, and Dispersal in the Brainstem of the Chicken Embryo
}

\author{
Sharon G. Hemond and Joel C. Glover \\ Department of Physiology, Institute of Basic Medical Science, University of Oslo, N-0317 Oslo, Norway
}

Retroviral-mediated gene transfer was used to study clonal patterns of proliferation, migration, and dispersal in the brainstem of the chicken embryo. Clones were generated at stages 13-17 (Hamburger and Hamilton, 1951), a period of neurogenesis in the brainstem neural tube subsequent to the formation of rhombomeres. Clones were examined in separate experiments at stages 24-27, when many neurons migrate and differentiate; at stages 28-29, when brainstem nuclei begin to form; and at stages 34-35, when brainstem nuclei are fully formed. Stages 24-29 are characterized by a general variability in proliferative kinetics and migratory behavior. Clone sizes range from 1 to 29 cells, and migration patterns range from strictly radial (i.e., normal to the ventricular surface) to combined radial and tangential (i.e., perpendicular to the radial component). There is, however, an underlying systematic variation: (1) clones exhibiting tangential migration contain on average more cells than clones exhibiting only radial migration, and (2) the proportion of tangentially migrating clones increases from medial to lateral. By stages 34-35 some individual clones have apparently dispersed to disparate neuronal groups.

The regional diversity observed among clones suggests that position along the mediolateral axis may determine the proliferative potential of progenitors and the migratory behavior and subsequent dispersal of their descendants.

[Key words: cell lineage, rhombomere, radial glia, recombinant retrovirus, gradient, hindbrain]

The proliferative and migratory stages of neural development bear an intimate relationship to the patterning of the nervous system. Local variation in proliferative rates and cell dispersal can directly affect the number and disposition of cells in different regions. Moreover, as populations of postmitotic cells are generated and migrate to their definitive positions, they are influenced by cnvironmental signals such as ccll or cxtraccllular matrix contacts and local sources of diffusible molecules. The extraordinary phenotypic diversity that results even within en-

\footnotetext{
Received Apr. 21, 1992; revised Sept. 21, 1992; accepted Sept. 28, 1992.

We thank Grete Steensland and Håvard Tønnesen for invaluable technical assistance, Knut Liestøl for expert advice on the statistical treatment of the data, and Marla Luskin, Cynthia Forehand, D. Kent Morest, Joshua Sanes, and Jan Jansen for reading and commenting on an earlier version of the manuscript. Josh Sanes provided a gift of the LZ10-producing cell line, and Friedrich Bonhoeffer provided a gift of the R5 antibody. This work was supported by Dr. med. Letten F. Saugstad's Fund (S.G.H.), the Fridtjof Nansen Fund (I.C.G.), and The Norwegian Medical Research Council.

Correspondence should be addressed to Dr. Joel C. Glover, Department of Physiology, Institute of Basic Medical Science, University of Oslo, Box 1103 Blindern, N-0317 Oslo, Norway.

Copyright (C) 1993 Society for Neuroscience $0270-6474 / 93 / 131387-16 \$ 05.00 / 0$
}

sembles of closely neighboring neurons attests to the complexity of interactions that may occur. To understand the morphogenesis and regional differentiation of the nervous system therefore requires a detailed description of the lineage, migratory patterns, and environmental histories of its constituent cells. Recent technical advances have facilitated such description: single progenitor cells can be labeled by dye-filled microelectrodes or by recombinant retroviruses, and the generation and subsequent migration of neurons and glia can be examined in the resultant clones. This approach has been used to study laminar structures, such as the retina (Turner and Cepko, 1987; Holt et al., 1988; Wetts and Fraser, 1988; Turner et al., 1990), optic tectum (Gray et al., 1988; Galileo et al., 1990), and cerebral cortex (Luskin et al., 1988; Price and Thurlow, 1988; Walsh and Cepko, 1988; Austin and Cepko, 1990; Grove et al., 1992; Parnevelas et al., 1992), in which cells migrate into layers concentric with the germinal epithelium, and structures with a predominantly nuclear organization, such as the spinal cord (Leber et al., 1990; Stern ct al., 1991), in which the definitive cytoarchitecture bears little resemblance to the original epithelial structure of the neural tube.

The brainstem contains relay and information processing centers that link the cerebrum, the cerebellum, and the spinal cord. These centers are assembled into an intricate architectural complex covering the spectrum of structural motifs, from laminar to nuclear to reticular. In accord with its many functions, the brainstem contains a myriad of neuronal phenotypes. The regional diversity of phenotype and structure in the brainstem provides an obvious motivation for studying lineage and migratory histories and their relationship to regional patterns of cell differentiation. Yet relatively little is known about cell lineage in the brainstem, and neuronal migratory patterns have been detailed only for a few populations of brainstem neurons of undetermined clonal relationship (Harkmark, 1954; Peusner and Morest, 1977; Puelles, 1978; Moody and Heaton, 1981; Clarke, 1982a; Book and Morest, 1990). In the one direct analysis of cell lineage and clonal patterns of migration published to date, Fraser et al. (1990) injected fluorescent lineage tracers into single progenitor cells in the chicken embryo at the neural plate and early neural tube stages (stages 6-12, Hamburger and Hamilton, 1951), and examined the resultant clones 1-2 d later (stages 18-19). They observed that the dispersal of clonal cohorts is restricted by the boundaries between rhombomeres (the transient neuromeres of the brainstem), such that each rhombomere can be considered a polyclonal compartment (Lumsden, 1990). During the developmental period of their study, however, only a small proportion of brainstem neurons has begun to migrate and differentiate. Many of the cells in the clones Fraser et al. (1990) observed are probably progenitor cells generated during a phase of progenitor proliferation. 
We wished to examine later stages, when much of the final complement of neurons is migrating and differentiating. Here we report clonal patterns of proliferation and dispersal in the chicken brainstem as assayed by the retroviral lineage tracing technique. The period of study covers a week of embryonic development, beginning at stage 13 (day 2) and ending at stage 35 (day 9), by which time the major nuclei of the brainstem are evident (Harkmark, 1954; Tan and LeDouarin, 1991). Our observations show that clones in the brainstem exhibit regional diversity in proliferation and migration, and suggest that clonal cohorts can disperse to colonize disparate and functionally distinct brainstem nuclei.

A preliminary account of some of these results has appeared (Hemond and Glover, 1991).

\section{Materials and Methods}

Virus injections. The recombinant retrovirus LZ10 (described in Galileo et al., 1990) was used to label individual progenitor cells and their progeny. LZ10 is produced by a helper cell line (kindly provided by J. Sanes) derived by the independent integration of the LZ10 construct and Rous sarcoma viral genes into the genome of the QT6 quail fibroblast cell line. The LZ10 construct contains the neo gene, which enables the selection of LZ10-producing QT6 cell lines, and the lacZ gene, which encodes the cytoplasmic enzyme $\beta$-galactosidase that serves as the cellular marker for localizing LZ10-infected clones. The LZ10 helper cell line was maintained as described by Sanes et al. (1986). Virus was harvested from culture supernatant, concentrated by centrifugation (Galileo et al., 1990), collected in an equal volume of dimethyl sulfoxide or fetal calf serum, titered, and stored in liquid $\mathrm{N}_{2}$. The titer of the concentrate ranged from 1 to $2 \times 10^{5}$ virions $/ \mathrm{ml}$ as determined by infection of QT6 fibroblasts.

White Italian chicken eggs were incubated in a forced-draft, humidified incubator at $37^{\circ} \mathrm{C}$. A window was cut in the egg and the embryo was staged according to Hamburger and Hamilton (1951). Injections of virus were performed at stages 13-17 (2-3 d of embryonic development). Just prior to injection, $1.5 \mu \mathrm{l}$ of $1 \%$ fast green dye was mixed with 30 $\mu \mathrm{l}$ of freshly thawed virus to aid in visualization, and $1.5 \mu \mathrm{l}$ of a $2 \mathrm{mg} /$ $\mathrm{ml}$ solution of polymethobromide (Polybrene, Sigma Chemical Co.) was added to increase the efficacy of infection (Sanes et al., 1986). After the vitelline membrane was teased away with electrolytically sharpened needles, the viral concentrate was pressure injected into the ventricular space with a picopump (model PV830, World Precision Instruments, New Haven, CT). Approximately $0.3-0.4 \mu$, containing from 30 to 80 virions, was injected into the lumen of the neural tube of each embryo. The injected volume was visible because of the fast green dye, and filled the fourth ventricle and the ventricle of the optic tectum. We routinely injected enough to fill both ventricles to minimize diffusion from the fourth ventricle. We estimate that less than half the injected volume was contained within the fourth ventricle, such that the brainstem neuroepithelium was exposed to about $15-40$ virions. The eggs were sealed with tape and returned to the incubator to develop to the desired stages. The half-life of a similar recombinant murine retrovirus ( $L Z 1$, described in Sanes et al., 1986) has been estimated to be $4 \mathrm{hr}$ at $37^{\circ} \mathrm{C}$ (J. C. Glover and J. R. Sanes, unpublished observations).

Histology. Embryos were removed into ice-cold phosphate-buffered saline (PBS) and decapitated. Whole heads (stages 24-29) or isolated brainstems (stages 34-35) were reacted for $\beta$-galactosidase activity as follows. Tissue was fixed with $2 \%$ formaldehyde, $0.03 \%$ glutaraldehyde in $0.1 \mathrm{~m}$ phosphate buffer $(\mathrm{pH} 7.4)$ for $1.5-2 \mathrm{hr}$. Tissue was stained for lac $Z$ overnight either at room temperature or at $37^{\circ} \mathrm{C}$ (no difference in staining at the two temperatures) with a solution of 5-bromo-4-chloro3 -indolyl- $D$-galactoside (X-Gal; $0.8 \mathrm{mg} / \mathrm{ml}$; Sigma), $20 \mathrm{~mm}$ potassium ferrocyanide, $20 \mathrm{~mm}$ potassium ferricyanide, $2 \mathrm{~mm} \mathrm{MgCl}_{2}$ in PBS. The detergents NP-40 (0.1\%) and deoxycholate $(0.5 \%)$ were added to improve reagent penetration of the tissue. After whole-mount inspection, the brainstems were postfixed in $2 \%$ formaldehyde, $2 \%$ glutaraldehyde, embedded in $17.5 \%$ gelatin, and sectioned at $200 \mu \mathrm{m}$ on a vibratome. Sections were cleared in glycerol and examined on a Leitz Ortholux II microscope. Selected sections were reembedded, sectioned on a cryostat, and processed for immunohistochemistry as described helow.

Clone analysis and statistical tests. Digitized images of all sections containing labeled cells were made with a video camera and the Zeus
Image Analysis system (Pixelwerks, Bergen, Norway). Selected sections were also photographed and/or traced with a camera lucida. To determine the longitudinal extent of clones, some $200 \mu \mathrm{m}$ sections containing stage $24-29$ clones were resectioned at $16 \mu \mathrm{m}$ in the transverse plane, and all $200 \mu \mathrm{m}$ sections containing stage 34-35 putative clones were resectioned at $100 \mu \mathrm{m}$ in the sagittal plane. Mediolateral variability in clone characteristics was for the most part analyzed on a regional basis, wherein the transverse plane was divided into floor plate, medial, lateral, and rhombic lip regions. The floor plate is demarcated from the medial region by a border that can be seen with Nomarski optics in unstained sections, with neutral red counterstaining, or with immunohistochemical staining of intermediate filaments. The rhombic lip is not well delineated in the chicken embryo because the outer lip furrow is lacking (Harkmark, 1954). It is conventionally defined as the region where the roof plate adjoins the alar plate and including about $100 \mu \mathrm{m}$ medial to that juncture (Harkmark, 1954; Book and Morest, 1990). The border between medial and lateral regions was defined by the sulcus limitans if it was obvious, or, where the sulcus limitans was not obvious, by dividing the region between the rhombic lip and the floor plate into equal halves. Databases of stage 24-29 clone characteristics were generated and analyzed using the Microsoft EXCEL and STATVIEW softwarc packages on a Macintosh II computer.

The statistical significance of differences in proportions was determined with $\chi^{2}$ contingency tests. All other statistical comparisons were made with nonparametric tests exclusively: the Mann-Whitney $U$ test for determination of difference of means, and the Kendall $t$ test for correlations. The latter provides a measure of the correlation between rank values of two variables, and is used to determine the statistical significance of correlations that are not necessarily dependent on a linear relationship between variables, for example, relationships in which one variable ranges from zero to a maximum, where the maximum is dependent on the second variable. The correlation coefficient $(t)$ is similar to the correlation coefficient obtained by linear regression and is not particularly useful alone. More important is the level of significance, which is expressed as the probability that the correlation between the observed paired rankings could be generated by random sampling from all possible paired rankings of the data set. Statistical tests performed with the computer were in some cases cross-checked manually using Hogg and Craig (1970) as a reference.

Immunocytochemistry. The R5 monoclonal antibody, directed against intermediate filament proteins, is an IgM produced by a hybridoma generated by Ursula Drager and was kindly provided by Friedrich Bonhoeffer. A monoclonal antibody against vimentin (catalog \#1112457) was purchased from Boehringer Mannheim Biochemica. Twelve embryos at stages 14-28, in addition to the LZ10-injected embryos, were used for immunohistochemical analyses. Whole embryos (stages 1423 ) or embryo heads (stages $24-28$ ) were fixed in $4 \%$ formaldehyde in $0.1 \mathrm{~m}$ phosphate buffer ( $\mathrm{pH} 7.4$ ). These preparations, or $200 \mu \mathrm{m}$ sections containing clones, were then rinsed, transferred through an increasing series of sucrose to a final concentration of $30 \%$, and infiltrated with gelatin ( $7.5 \%$ in a $30 \%$ sucrose solution) for $3 \mathrm{hr}$ at $37^{\circ} \mathrm{C}$ before freezing in liquid $\mathrm{N}_{2}$. Sections were cut on a cryostat (Reichert-Jung, model $2700)$ at $16 \mu \mathrm{m}$ in a plane transverse to the notochord and could be stored at $-20^{\circ} \mathrm{C}$ for up to 1 week with no apparent detriment. Sections were pretreated first with phenylhydrazine $(0.05 \mathrm{M})$ to quench endogenous peroxidase activity (Straus, 1972), then with normal horse serum (1\%) to block nonspecific staining of the secondary antibody, and Triton $\mathrm{X}-100(0.5 \%)$ to facilitate antibody penetration of the tissue. The primary antibody was visualized with a biotin-streptavidin-horseradish peroxidase system (Vectastain Laboratories ABC. kit, Burlingame, CA) using diaminobenzidine as the chromogen. Labeling was intensified with cobalt and nickel (Adams, 1981).

\section{Results}

We infected embryos with LZ10 at stages 13-17, an approximately $12 \mathrm{hr}$ period during the early stages of neuronal proliferation and just after the formation of all rhombomere boundaries (Vaage, 1969). Infected embryos were then allowed to develop to one of three different endpoints: (1) stages 24-27, when many neurons are born and have begun migrating, and the brainstem neural tube still has a relatively simple epithelial organization; (2) stages $28-29$, when some brainstem nuclei first become recognizable with conventional histological procedures; 
and (3) stages 34-35, when most brainstem nuclei are fully formed (Harkmark, 1954; Tan and LeDouarin, 1991). LacZlabeled cells or cell clusters could be seen from the ventricular surface of whole-mount preparations at stages 24-29, and in $200 \mu \mathrm{m}$ transverse sections at stages $34-35$. Only one abnormality was observed among the LZ10-infected brainstems: one brainstem had an outgrowth of the ventricular zone that contained a labeled cluster. Presumably the injection micropipette had penetrated the neural tube and disturbed normal morphogenesis at the injection site. This cluster was not included in subsequent analysis.

\section{Definition of clones, stages 24-29}

The definition of retrovirally labeled cell clusters as single clones is often based on the premise that discrete, spatially isolated cell clusters arising at low frequency are each unlikely to be generated by more than one viral infection. Viral dilution experiments (Turner and Cepko, 1987; Gray et al., 1988), the use of two discriminable viral markers (Galileo et al., 1990; Leber et al., 1990), and statistical analyses (Grove et al., 1992) have supported this premise in other studies. Here, we injected only a few (about 15-40) virus particles into the ventricle of each brainstem. Of 289 embryos injected with LZ10, 175 survived to stages 24-27 and 33 survived to stages 28-29. We found 213 lac Z-labeled cell clusters or isolated single cells in 54 of these 208 brainstems, or an average of about four per brainstem for brainstems that contained labeled cells (range, 1-32), but only about one per brainstem for all brainstems. The latter value gives the apparent infection rate (which equals the actual infection rate if all infections produce lac $Z$-expressing clones). We do not know why the injection of an estimated 15-40 virus particles led to so few infections on average. One possibility is that only a fraction of cells in the brainstem ventricular zone express receptors recognized by LZ10. Another possibility is that many of the injected virus particles were carried out of the ventricle of the brainstem by leakage or by movements of the cerebrospinal fluid before infection could occur. In any case, with such a low apparent infection rate it is improbable that any given cluster arose from two separate but closely spaced infection events (see Grove et al., 1992). Moreover, most clusters $(96 \%)$ had discrete contacts with the ventricular zone that were probably their sites of origin (Fig. 1). On these counts each cluster is likely to be a discrete clone.

An issue that is more difficult to resolve is whether a cell cluster represents an entire clone. One formal possibility is that a clone might split into two or more clusters that become separated. Such separation, however, would be limited at early stages by the intrinsic barriers to migration represented by the rhombomere boundaries and the midline (Fraser et al., 1990). Although the rhombomere boundaries are no longer apparent after stage 29 , later longitudinal migration evidently is not appreciable until after stage 34 (Tan and LeDouarin, 1991). Known examples of later neuronal migration across the midline do not occur until after stage 27 (Harkmark, 1954; Puelles, 1978; Tan and LeDouarin, 1991).

Based on these considerations, a labeled cell or cell cluster at stages 24-29 was defined as a clone if it satisfied one of the following three criteria: (1) it was the only labeled cell or cell cluster in a brainstem; (2) it was the only labeled cell or cell cluster in a rhombomere (stages 24-29) or a hemi-rhombomere (stages 24-27 only); (3) it was one of a few discrete cell clusters in a hemi-rhombomere (stages 24-27) or rhombomere (stages

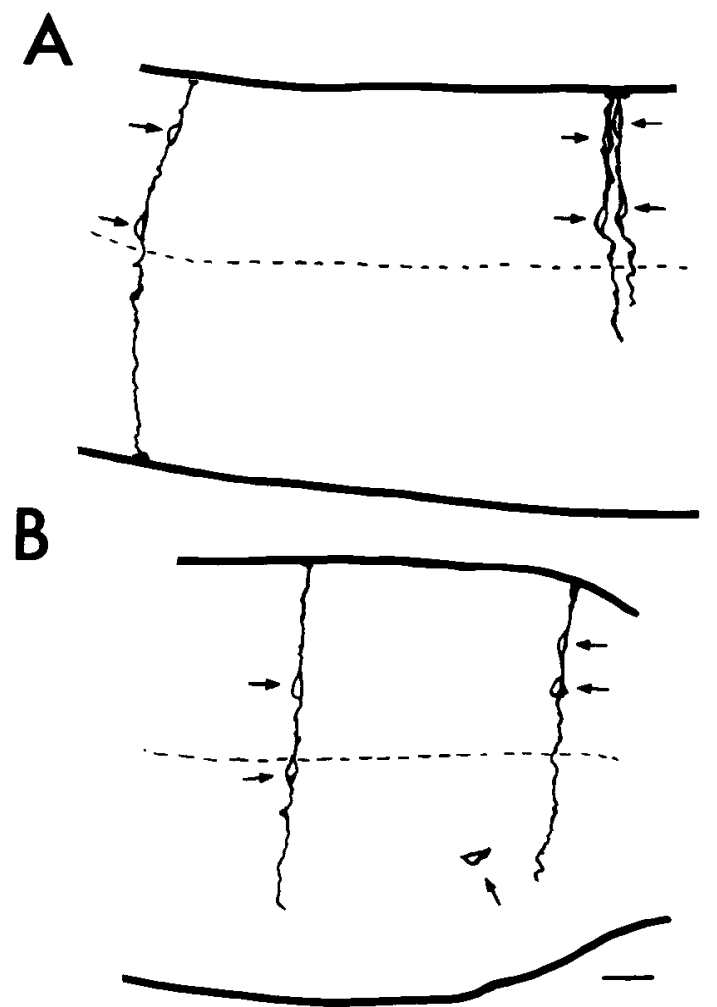

Figure 1. Camera lucida drawings of representative cell clusters at stage 24-25, shown in transverse section. The position of the cell body of each labeled cell is indicated by an arrow. $A$, Two clusters in rhombomere 5 , separated by $170 \mu \mathrm{m}$, have discrete ventricular origins and were defined as separate clones. Injection stage 14. $B$, Two clusters in rhombomere 6 , separated by $110 \mu \mathrm{m}$, are not distinct because the origin of the single outlier cell is ambiguous. Both clusters were excluded from further analysis. Injection stage 15.5. Scale bar, $20 \mu \mathrm{m}$.

28-29), each of which had a discrete contact with the ventricular surface. The clones defined by criterion 3 included seven pairs and one triplet of clones in single hemi-rhombomeres, and six pairs, four triplets, and one quadruplet of clones in single rhombomeres. Here we make the assumption that each ventricular contact represents the location of the single retrovirally labeled progenitor that gave rise to all of the cells in the cluster. Since the clones defined by this criterion were essentially similar to those defined by criteria 1 and 2 (they had the same average number of cells and a similar distribution of clone morphologies), we feel that they are also representative of single, complete clones generated at the time of infection. We excluded from analysis, however, any clusters whose cells were arrayed in such a way that the assignment of cells to each cluster was ambiguous. An example of two closely neighboring clones defined by criterion 3 is shown in Figure $1 A$, while an example of two closely neighboring clusters that did not satisfy criterion 3 is shown in Figure $1 B$. To summarize, a cluster was defined as a clone if it was isolated and its migration could be traced from a discrete proliferative site in the ventricular zone, or if it was segregated from other clusters by intervening migratory barriers, or both.

\section{Clone size and morphology, stages 24-29}

Using the above criteria, 78 clusters were defined as clones at stages $24-27$ and 53 clusters were defined as clones at stages 28-29. The remainder of the lacZ-labeled cell clusters ( 82 of $213,38 \%$ ) were excluded from analysis. Comparison of the size distribution of clones and of all labeled clusters shows that ex- 

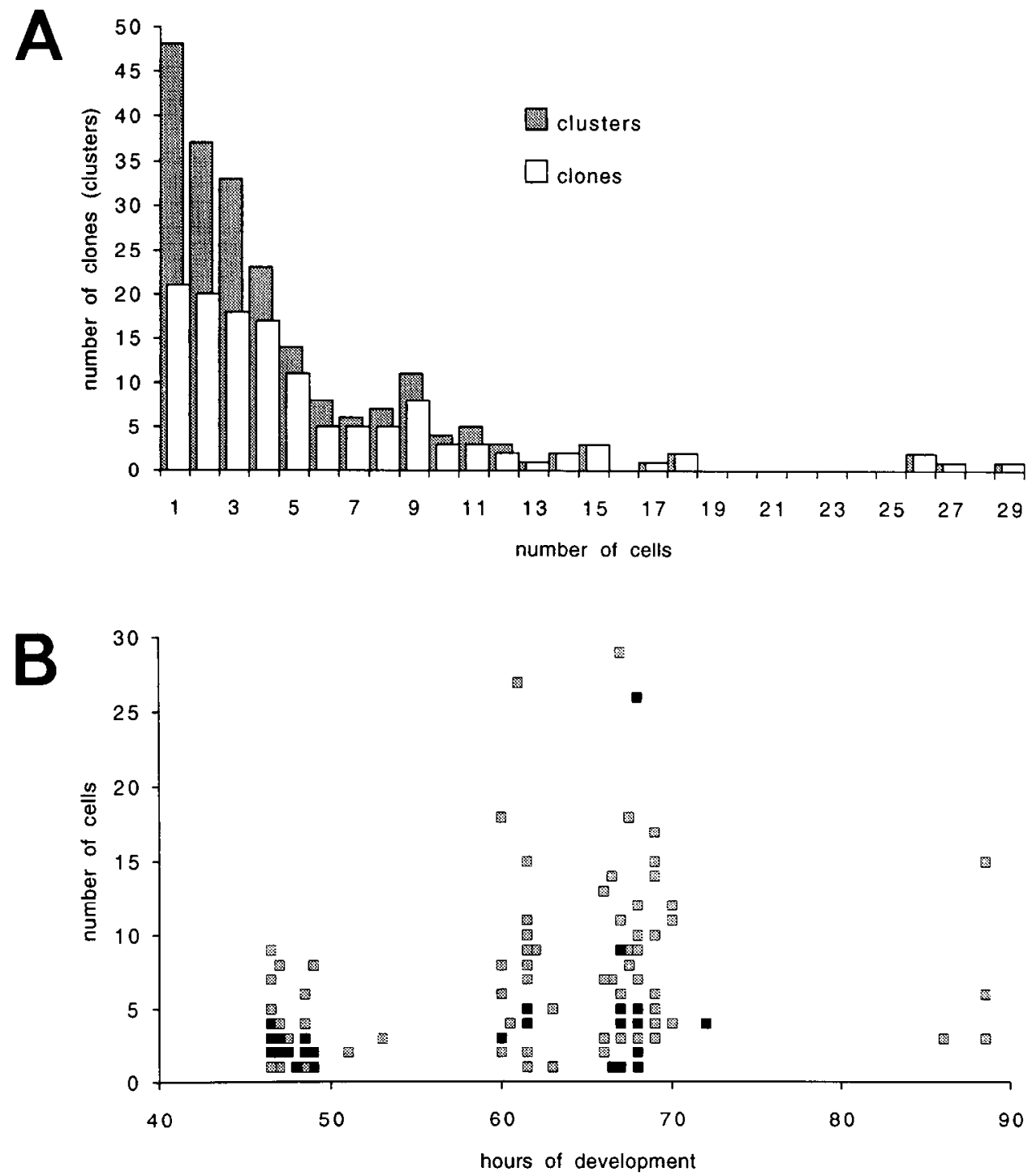

Figure 2. A, Histogram of the size of clones and of the clustcrs from which clones were defined. $B$, Clone size tends to increase with survival time, but is highly variable for any given survival time. Survival time (expressed in hours of development) represents the time from LZ10 injection to death, and is independent of the embryonic stage at which injection occurred. Solid symbols represent multiple data points (ranging from two to six). clusion was predominantly of one to four cell clusters (Fig. 2A). This is because single cells and clusters with few cells were the most difficult to define unambiguously as clones by our criteria and were consequently excluded from analysis disproportionately. The possibility of errors introduced by biased sampling is considered in the Discussion.

The 131 clones were distributed throughout the rostrocaudal and mediolateral extents of the caudal brainstem (Fig. $3 A$ ). The majority $(66 \%)$ contained one to five cells, with an average of $5.6 \pm 5.4$ cells (range, 1-29) for all clones. Since proliferation is still occurring in some parts of the brainstem at stages 24 29 , we expected that some of the variability in the number of cells per clone was due to differences in the stage at which LZ10 was injected and in the time between injection and death (these two parameters differ slightly because neither the stage of injection nor the stage of death was held constant). A general trend was seen in both cases: clone size tended to decrease with later injections and to increase with increasing survival time (Fig. $2 B)$. Neither of these trends, however, could be fit by a regression line within statistically significant limits. This is because cell number per clone was highly variable even when stage of injection and survival time were constant. For example, in 12 clones that were generated from injections at stage 14 and that had survival times of $61 \mathrm{hr}$, clone size still ranged from 1 to 27 cells. Stage 28-29 clones were larger on average than stage 2427 clones, but because of the high variability the difference was not statistically significant, and the two groups have been lumped in the following analyses.

Transverse views of $200 \mu \mathrm{m}$ sections suggested that all stage 24-29 clones were spatially compact in the longitudinal axis, and that cell dispersal was restricted primarily to the transverse plane. Serial sectioning of several representative clones at 16 $\mu \mathrm{m}$ corroborated this and suggested that no clone spanned more than about $50 \mu \mathrm{m}$ in the longitudinal axis. The number of cells recovered in $16 \mu \mathrm{m}$ sections matched the number observed in the $200 \mu \mathrm{m}$ sections. To characterize clone morphology further, clones were classified as radial, radial with outliers, or nonradial, on the basis of their appearance in the transverse plane. Radial clones (Figs. $4 B, C, E, F ; 5 D, F$ ) were those in which the constituent cells lay in a coherent or coaxial stream, roughly aligned with the predominant trajectory of radial fibers revealed by antibodics against intermediatc filaments (see below). The majority $(72 \%)$ of clones were radial. Radial with outlier clones (Figs. $4 A, 5 C$ ) resembled radial clones except that some cells deviated from the radial stream, usually on a tangentially oriented trajectory. Nonradial clones (Fig. $4 D$ ) were those that 

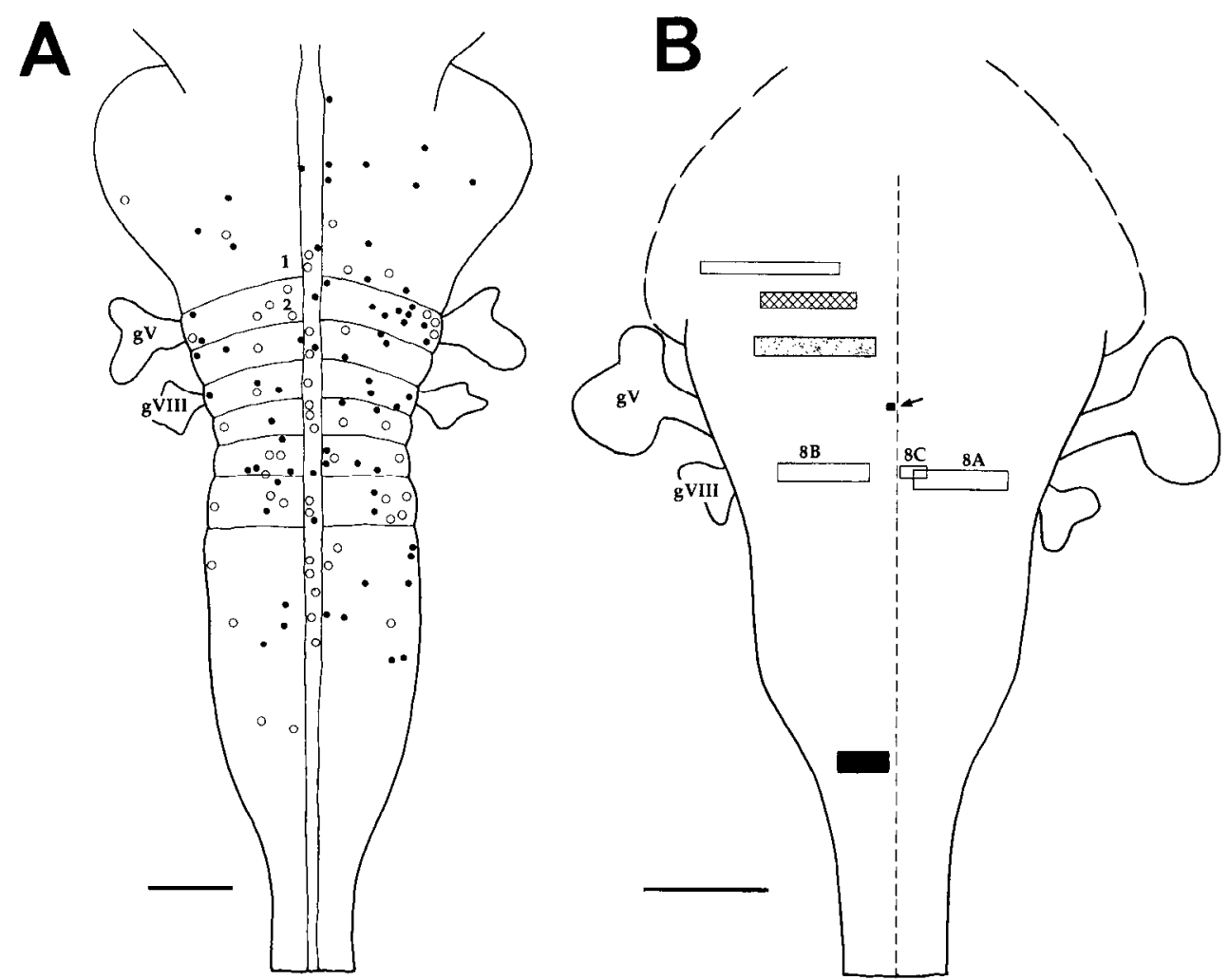

Figure 3. The clones and putative clones analyzed in this report are distributed throughout the caudal brainstem. $A$, The location of each clone (solid circles, stage 24-27; open circles, stage 28-29) is indicated on a camera lucida drawing of the ventral aspect of a stage 26 brainstem. To assist the identification of rhombomeres, rhombomeres $I$ and 2 are indicated by number; there are eight rhombomeres in all. $B$, The locations of the eight stage 34-35 putative clones, derived from seven different brainstems, are indicated on a camera lucida drawing of the ventral aspect of a stage 35 brainstem. The mediolateral and rostrocaudal extents of the clones were measured in transverse sections and are depicted by rectangles. Each unshaded rectangle represents a putative clone derived from a brainstem that contained no other labeled cells. The two solid rectangles represent two putative clones derived from one brainstem that contained no other labeled cells (the smaller of the two, a floor plate clone, is marked by an arrow). The cross-hatched and stippled rectangles each represent a putative clone derived from a brainstem that contained other labeled cells that could not be defined as putative clones because of their dispersal. These labeled cells were located at least $1 \mathrm{~mm}$ along the longitudinal axis from the putative clone. Putative clones designated $8 \mathrm{~A}, 8 \mathrm{~B}$, and $8 \mathrm{C}$ are shown in camera lucida drawings in the respective panels of Figure 8 . Rostral is up in both panels. $g V$, trigeminal ganglion, $g V I I I$, vestibular/acoustic ganglionic complex. Scale bars: $A, 500 \mu \mathrm{m} ; B, 1 \mathrm{~mm}$.

contained only one or two cells with no ventricular attachment, or those in which all the constituent cells were aligned tangentially.

All but three of the radial and radial with outlier clones contacted the ventricular surface. These contacts presumably represent the sites of clonal origin, that is, the ventricular positions of the clonal progenitors. About one-third of the clones also contacted the pial surface with end-foot structures that are characteristic of neuroepithelial progenitors during the non-mitotic phases of the cell cycle. Floor plate clones were distinctive because they were composed entirely of cells that spanned from the ventricular surface to the pial surface (Fig. $4 E, F$ ). In floor plate clones containing single cells, it was possible to discern branched pial end feet and short cellular appendages oriented normal to the cells' radial axes (Fig. $5 F$ ).

The cells in radial clones and in the radial components of radial with outlier clones were typically contiguous. In some cases the contiguity was mediated by direct contact between cell bodies; in other cases, by contact between processes. Outlier cells were sometimes contiguous as well. Often, however, outlier cells appcared isolated from onc another and from their radial stream of origin. Outlier cells were concentrated in the lateral region of the mantle zone (Fig. 6). Most outlier cells (about 90\%) were located medial to their radial stream of origin, but six clones contained lateral outliers.
Nonradial clones did not contact the ventricular zone, and their constituent cells were not contiguous (Fig. 4D). It was therefore impossible to infer their sites of origin or migratory histories. This class of clone was the least frequent $(n=3)$ and contained the fewest cells (Table 1).

In 48 clones, all of which were radial, the cell bodies were restricted entirely to the ventricular zone. One or more processes extended radially into the mantle zone, sometimes as far as the pial surface. These radial clones were significantly smaller on average than the other radial clones (Table 1), but nevertheless ranged from 1 to 10 cells in size. Most of the one-cell clones (17 of 21 ) were in this group. Clones of this type were particularly common in the floor plate (Table 2), as expected, since the nuclei of floor plate cells typically remain in the ventricular zone. Another neural cell type, the ependymal cell, also remains at the ventricular surface in regions outside the floor plate. However, it is possible that many of the clones we observed outside the floor plate whose cell bodies were restricted to the ventricular zone are not clones of ependymal cells but rather of "premigratory" cells that will eventually leave the ventricular zone.

\section{Potential migratory substrates, stages 24-29}

The clone morphologies observed at stages 24-29 suggested at least two different directions of cellular migration, radial and tangential. However, the morphogenesis of the brainstem com- 


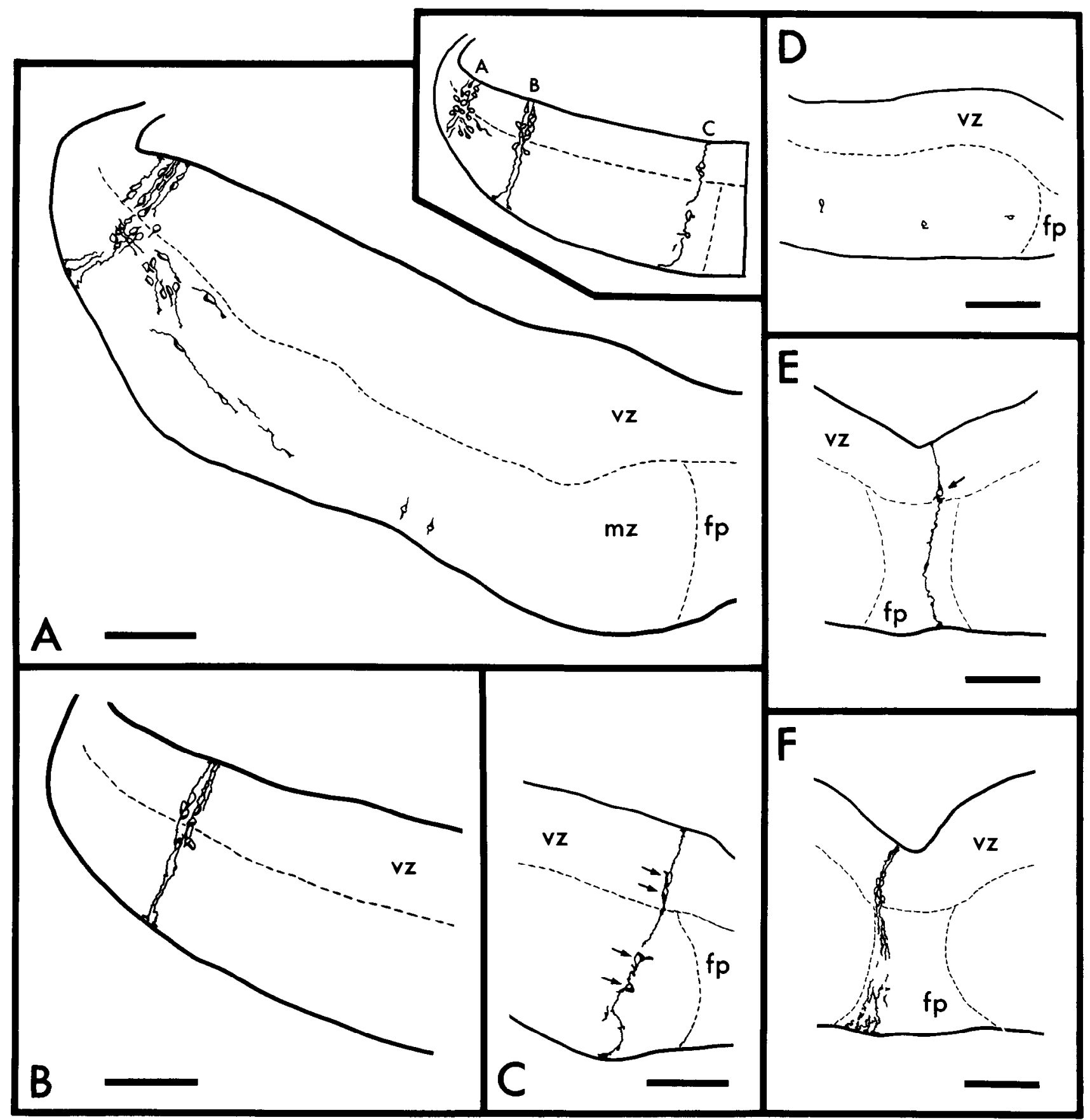

Figure 4. Camera lucida drawings showing representative examples of different clone morphologies at stages $24-26$ seen in $200 \mu \mathrm{m}$ transverse sections. Dorsal is up. Inset shows the relative mediolateral locations of the clones in $A-C$. Individual cell bodies are indicated by arrows in $C$ and $E$. $A$, Radial clone with outliers ( 27 cells) originating from the rhombic lip in rhombomere 4 . The radial component contacts the pial surface with end-foot structures characteristic of primitive neuroepithelial cells. Outlier cells leave the radial component in the mantle zone to course tangentially toward the midline. $B$, Radial clone $(11$ cells) in the lateral region in rhombomere 6 . $C$, Radial clone (four cells) in the medial region in rhombomere 6. $D$, Nonradial clone (three cells) in rhombomere 2. $E$, One-cell radial clone in the floor plate in rhombomere $2 . F$, Eight-cell radial clone in the floor plate in rhombomere 1. Many if not all of the cells in this clone extend processes to the pial surface. The border between the mantle and marginal zones is not shown here but can be seen in Figure 5. The clones in $A$ and $B$ are also shown in Figure 5, $C$ and $D$, respectively, but are not visible in their entirety in the focal plane of the photographs. $f n$, floor plate; $v z$, ventricular zone; $m z$, combined mantle and marginal zones. Scale bars: $A, 200 \mu \mathrm{m} ; B$ and $D, 150 \mu \mathrm{m} ; C ; E$, and $F, 100 \mu \mathrm{m}$.

plicates the definition of radial and tangential axes, especially at and near the rhombic lip. Therefore, to determine the relationship between migratory trajectories and potential migratory substrates, we stained radial glia with the R5 antibody and antibodies against vimentin (Drager, 1984; Vanselow et al., 1989). We describe below the pattern of R5 immunoreactivity at stages representative of the time of virus injection (stage 14) and of clone description (stages 24-26). Vimentin immunoreactivity was virtually the same and will not be described separately.

At stage 14, R5 immunoreactivity was found almost exclusively at the pial surface, where the end feet of neuroepithelial 

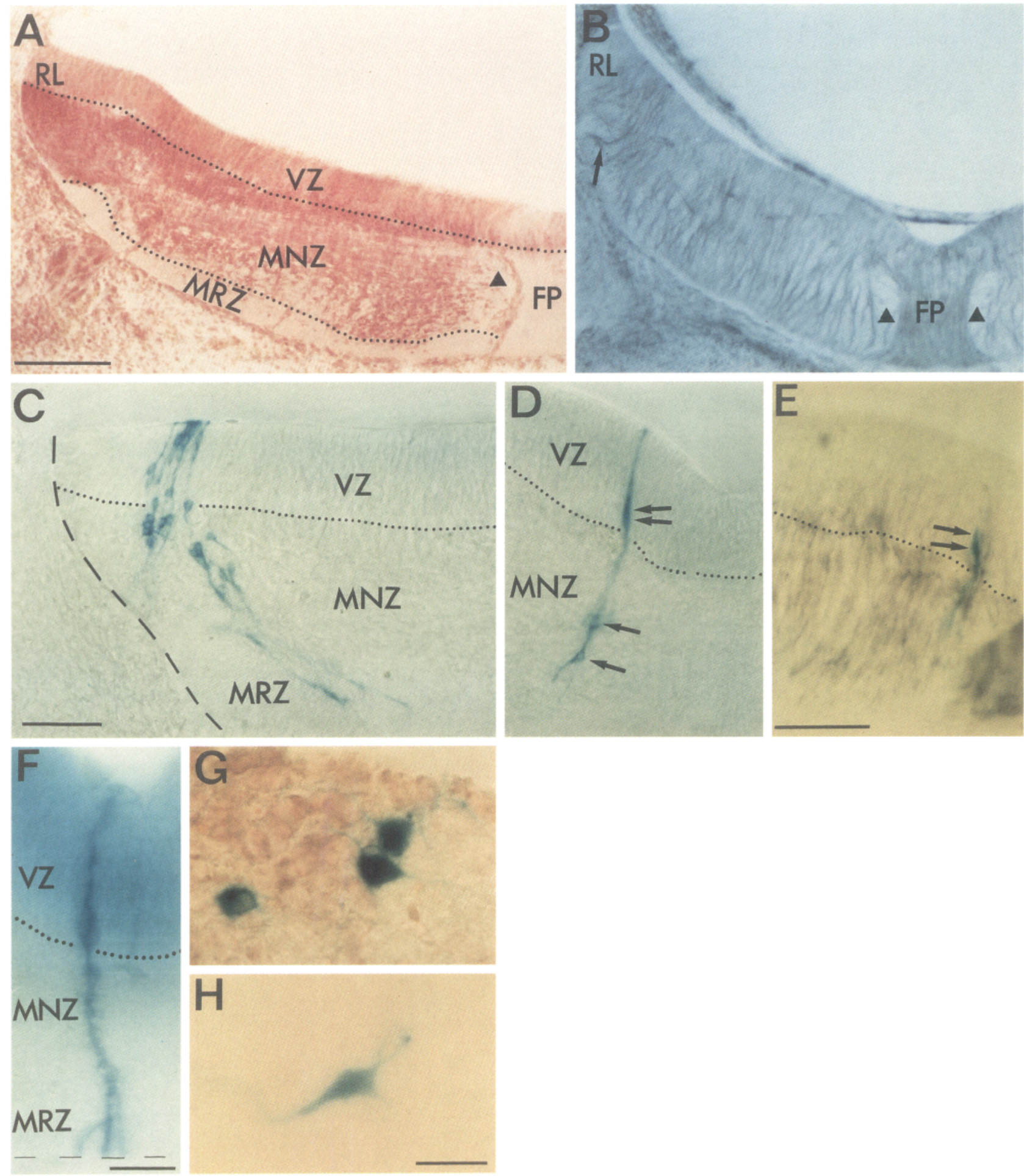

Figure 5. A, The dorsoventral zones as visualized in a $16 \mu \mathrm{m}$ section stained with neutral red, stage 26, rhombomere 5. B, The trajectory of R5positive fibers as seen in a $16 \mu \mathrm{m}$ section, stage 26 , rhombomere 4 . R5-positive fibers have a roughly radial trajectory, but deviate in regions of cranial nerve entry, as for the VIIIth nerve (arrow), and fiber tracts, as for the medial longitudinal fascicle (triangles). In this section, the roof plate has collapsed and lies directly on the ventricular surface. $C$, Twenty-seven-cell rhombic lip clone in rhombomere 4 , photographed in a $200 \mu \mathrm{m}$ transverse section (stage 26, after virus injection at stage 14). The dashed line indicates the pial surface. This clone is shown in its entirety in the camera lucida drawing in Figure 4A. D, Four-cell radial clone in rhombomere 6, photographed in a $200 \mu$ m transverse section (stage 26, after virus injection at stage 14.5). Arrows indicate cell bodies. This clone is shown in its entirety in the camera lucida drawing of Figure $4 C$. $E$, Two cells (arrows), from the same clone as shown in $D$, are visible in a $16 \mu \mathrm{m}$ transverse cryostat section taken through the clone and immunostained for $\mathrm{R} 5$. The clone is aligned with the trajectory of R5-positive fibers. The dark patch at lower right is a fold in the section. $F$, One-cell clone in the floor plate in rhombomere 7, photographed in a $200 \mu \mathrm{m}$ transverse section (stage 24.5, after virus injection at stage 15.5). Short lateral appendages are visible along the cell's radial shaft, which branches near the pial surface (dashed line) to form multiple end feet. $G$ and $H$, Examples of differentiated neurons contained in stage 34-35 cell clusters, photographed in $16 \mu \mathrm{m}$ transverse sections. $G$, Motoneurons in the trochlear nucleus, counterstained with neutral red. $H$, A neuron in the reticular formation. $V Z$, ventricular zone; $M N Z$, mantle zone; $M R Z$, marginal zone; $F P$, floor plate; $R L$, rhombic lip. Dotted lines show the boundaries between VZ and MNZ $(A, C-F)$ and between MNZ and MRZ $(A)$. Scale bars: $A$ and $B$, $150 \mu \mathrm{m} ; C-E, 75 \mu \mathrm{m}$ (scale bar in $C$ applies to $D$ also); $F-H, 25 \mu \mathrm{m}$ (scale bar in $H$ applies to $G$ also). 
Figure 6. Tangentially migrating outlier cells and potential substrates for tangential migration are more prevalent in the lateral region of the brainstem at stage 24-29. $A$, The distribution of all outlier cells in stage 24-29 clones is shown on a schematic diagram of a hemisection of the brainstem. Each dot represents a single outlier cell. Dots with laterally directed arrows represent outlier cells located lateral to the radial component of their parent clone; all other outlier cells were located medial to the radial component of their parent clone. The box indicates the approximate location of the region shown in $B$. $B, \mathrm{R} 5$ immunoreactivity in the lateral brainstem. R5-positive radial fibers approach and often contact the pial surface (dashed line). Short R5-positive tangential fibers (arrows) occur near the border between mantle and marginal zones. $M N Z$, mantle zone; $M R Z$, marginal zone. Scale bar, $30 \mu \mathrm{m}$.
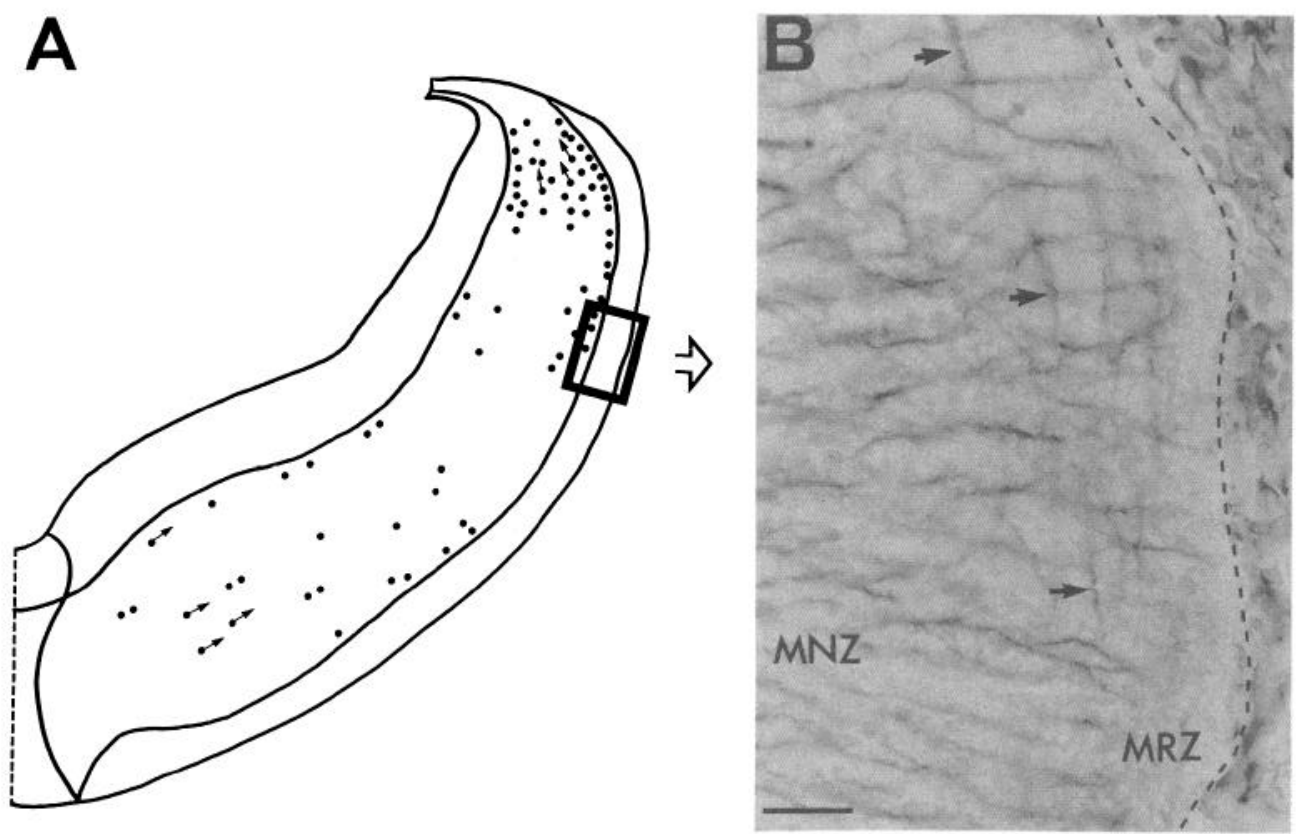

cells are located; only a few R5-positive radial fibers extended from the ventricular surface to the pial surface. By stage 24 , such radial fibers were apparent throughout the mediolateral and rostrocaudal extent of the brainstem (Fig. 5B). The fibers had a generally radial trajectory in all regions. However, individual trajectories appeared irregular and tortuous; fibers did not course smoothly and in parallel. The generally radial trajectory was disturbed in regions containing axon tracts or the entry zones of cranial nerves. Radial fibers near the floor plate, for example, often circumnavigated rather than penetrated the medial longitudinal fascicle (Fig. $5 B$, triangles), while radial fibers appeared tangled at the entry zone of the VIIIth nerve (Fig. 5B, arrow). The radial components of clones selected for immunohistochemical analysis were aligned with the trajectory of neighboring R5-positive fibers (Fig. $5 E$ ).

By stage 26, a second, smaller complement of R5-positive fibers had appeared that coursed tangentially. These few tangential fibers were most prevalent laterally, near the border between the mantle and marginal zones (Fig. 6, arrows). Occasional short R5-positive tangential fibers were seen just lateral

Table 1. Statistical characterization of clones of different morphological classes

\begin{tabular}{|c|c|c|c|c|}
\hline & \multicolumn{2}{|l|}{ Radial } & \multirow{2}{*}{$\begin{array}{l}\text { Radial } \\
\text { with outliers }\end{array}$} & \multirow[b]{2}{*}{ Nonradial } \\
\hline & VZ-restricted & Others & & \\
\hline Number of clones & 48 & 46 & 34 & 3 \\
\hline \multicolumn{5}{|l|}{ Cells/clone } \\
\hline $\begin{array}{l}\text { mean } \pm \mathrm{SD} \\
\text { (range) }\end{array}$ & $\begin{array}{l}2.7 \pm 2.1 \\
(1-10)\end{array}$ & $\begin{array}{l}5.2 \pm 4.5^{*} \\
(1-26)\end{array}$ & $\begin{array}{l}10.9 \pm 6.7^{* *} \\
(3-29)\end{array}$ & $\begin{array}{l}3.3 \pm 0.6 \\
(3-4)\end{array}$ \\
\hline \multicolumn{5}{|c|}{ Number of cell bodies } \\
\hline $\mathrm{VZ}$ & 129 & 133 & 172 & 0 \\
\hline MNZ & 0 & 105 & 188 & 10 \\
\hline MRZ & 0 & 1 & 10 & 0 \\
\hline \multicolumn{5}{|l|}{ Stage of infection } \\
\hline $\begin{array}{l}\text { mean } \pm \mathrm{SD} \\
\text { (range) }\end{array}$ & $\begin{array}{l}14.5 \pm 1.0 \\
(13-17)\end{array}$ & $\begin{array}{l}14.5 \pm 1.0 \\
(13-16.5)\end{array}$ & $\begin{array}{l}14.5 \pm 1.0 \\
(13-16.5)\end{array}$ & $\begin{array}{l}15.0 \pm 2.0 \\
(13-16.5)\end{array}$ \\
\hline \multicolumn{5}{|c|}{ Hours of development ${ }^{a}$} \\
\hline $\begin{array}{l}\text { mean } \pm \text { SD } \\
\text { (range) }\end{array}$ & $\begin{array}{l}59.0 \pm 8.9 \\
(46.5-70)\end{array}$ & $\begin{array}{l}60.0 \pm 11.3 \\
(46.5-88.5)\end{array}$ & $\begin{array}{l}65.0 \pm 9.2 \\
(46.5-88.5)\end{array}$ & $\begin{array}{l}62.5 \pm 13.1 \\
(47.5-72)\end{array}$ \\
\hline
\end{tabular}

VZ, ventricular zone; MNZ, mantle zone; MRZ, marginal zone.

${ }^{a}$ Hours of development represent time elapsed between injection and death, independent of stage of infection.

* Difference between radial clones restricted to VZ, and other radial clones; level of significance, $p<0.001$, MannWhitney $U$ test.

*** Difference between radial with outlier clones and radial clones (not restricted to VZ); level of significance, $p<0.001$, Mann-Whitney $U$ test. 


\begin{tabular}{|c|c|c|c|c|c|}
\hline & Floor plate & Medial & Lateral & Rhombic lip & Total \\
\hline \multicolumn{6}{|l|}{ Number of clones } \\
\hline All & 22 & 52 & 38 & 19 & 131 \\
\hline Radial & 22 & 41 & 24 & 7 & 94 \\
\hline$(\text { vz-restricted })^{a}$ & (17) & $(20)$ & (7) & (4) & $(48)$ \\
\hline Radial with outliers & 0 & 9 & 13 & 12 & 34 \\
\hline Nonradial & 0 & 2 & 1 & 0 & 3 \\
\hline \multicolumn{6}{|l|}{ Number of cells/clone } \\
\hline $\begin{array}{l}\text { mean } \pm \mathrm{SD} \\
\text { (range) }\end{array}$ & $\begin{array}{l}3.7 \pm 3.1^{*} \\
(1-10)\end{array}$ & $\begin{array}{l}4.5 \pm 3.5^{*} \\
(1-18)\end{array}$ & $\begin{array}{l}6.3 \pm 5.2^{*} \\
(1-26)\end{array}$ & $\begin{array}{l}11.1 \pm 8.8^{*} \\
(1-29)\end{array}$ & $\begin{array}{l}5.6 \pm 5.4 \\
(1-29)\end{array}$ \\
\hline
\end{tabular}

to the floor plate also. It was not clear whether these tangential fibers were branches of R5-positive radial fibers or whether they were a separate population.

\section{Mediolateral variability and the distinction between clone classes}

As a first step toward determining whether there was any systematic regional variation in the proliferative and migratory behavior of clones, we subdivided the mediolateral axis into four regions: floor plate, medial, lateral, and rhombic lip (Fig. 7). The entire clone population was evenly distributed along this axis. Comparison of the different clone populations with respect to the number of cells they contained showed that radial with outlier clones were larger on average than radial clones, and that the subpopulation of radial clones with cell bodies restricted to the ventricular zone were smaller on average than the other radial clones (Table 1). Moreover, the proportion of radial with outlier clones increased region for region along the mediolateral axis, while the proportion of radial clones restricted to the ventricular zone decreased (Fig. $7 A$ ). Thus, clone size and the prevalence of outlier cells both increased from medial to lateral, being highest in the rhombic lip (Table 2, Fig. 6A). This relationship was also apparent when clone size was plotted as a function of absolute distance from the midline (Fig. $7 B$ ).

The floor plate is morphologically and biochemically distinct from the other regions (Tessier-Lavigne et al., 1988; McKanna and Cohen, 1989; Wagner et al., 1990; Griffith and Sanders, 1991). Because this distinction might represent a discontinuity in the proliferative and migratory dynamics of the neuroepithelium, we tested the statistical significance of the mediolateral increase in clone size both with and without the floor plate clones. In both cases, the increase was statistically significant (Table 2, Fig. 7B).

The mediolateral gradient in clone size prompted us to examine more closely the potential origins of the differences among the clone classes. A reasonable hypothesis is that the three classes represent transitional forms in a developmental sequence of proliferation and clone maturation, in which newly generated cells first accumulate radially within the ventricular zone, then migrate radially out of the ventricular zone, and finally begin to migrate tangentially in the mantle zone. Consistent with such a sequence is the progressive, class-by-class translocation of cells out of the ventricular zone (Table 1 , row 3 ). If all clones were fated to complete this sequence, then any clone allowed to develop long enough would eventually become a radial with outliers clone, and we would expect clone class and size to be a function of the time elapsed between infection and death. However, neither the average stage of infection nor the average survival time differed significantly among the three clone classes (Table 1, rows 4 and 5; Kendall's $t$ correlation test for survival time, $p=0.35$ ). Thus, on the basis of these data, we must allow the possibility that the clone classes do not represent transitional forms, or, if they do, that they derive from progenitors with different average cell cycle times.

\section{Characterization of putative clones at stages 34-35}

The brainstem undergoes considerable growth and morphometric change between 5 and $9 \mathrm{~d}$ of embryogenesis (Harkmark, 1954). Although the length does not increase markedly, the thickness at the floor plate and the cross-sectional area both increase by up to threefold, depending on the rostrocaudal level. Much of this increase occurs in the ventral part of the basal plate with the emergence of large association nuclei like the olivary complex. The alar plate also develops a pronounced bulge at the ventricular surface associated with the growth and differentiation of dorsal sensory nuclei. Different regions along the longitudinal axis become pitched either rostrally or caudally with the appearance of the pontine flexure. To estimate the degree of cell dispersal generated during these changes, we infected a second set of embryos with LZ10 and allowed them to develop until stages 34-35, when many cell groups and nuclei have differentiated and established connections.

Of 81 embryos infected with LZ10 at stages 12-15, 50 survived to stages 34-35. Eleven of these contained lacZ-labeled cells. The proportion of brainstems with no labeled cells was similar to that seen at stages $24-29$ (39 of 50 vs 159 of 213 , or about $75 \%$ ), indicating an equally low apparent infection rate in the two groups. The pattern of labeling at stages 34-35 differed, however, from that seen at stages 24-29: labeled cells were much more dispersed, rarely contiguous, and rarely maintained contact with the ventricular surface. Moreover, rhombomere boundaries are no longer evident at stages 34-35, and the midline no longer functions as a barrier to migration. Thus, the three criteria used for defining clones at stages 24-29 were not valid at stages $34-35$.

Nevertheless, some labeled cells in stage $34-35$ brainstems 
Figure 7. A, The different clone classes exhibit mediolateral variation in their relative proportions. The columns for each mediolateral region sum to roughly $100 \%$ (a small discrepancy exists because the three nonradial clones have not been included). The proportion of radial clones with cells restricted to the ventricular zone decreases mediolaterally, while the proportion of radial with outlier clones increases. $B$, Clone size increases with distance from the midline. Shaded squares represent distances measured during direct microscopic examination; solid squares represent distances estimated from photographic reproductions or camera lucida drawings. The Kendall $t$ nonparametric correlation test was used to determine the statistical significance of this relationship. The probability that the distribution of points in the scatter diagram could be generated by random sampling from all possible rankings of clone size versus distance in the data set is $p$ $<0.001(t=0.32)$. The significance level remains high $(p<0.003)$ even after the elimination of all points at distances less than $50 \mu \mathrm{m}$ (which includes all floor plate clones), or of all points representing clone sizes of 10 or more cells. Elimination of both these sets of points, however, drops the significance level dramatically $(p=0.05)$.
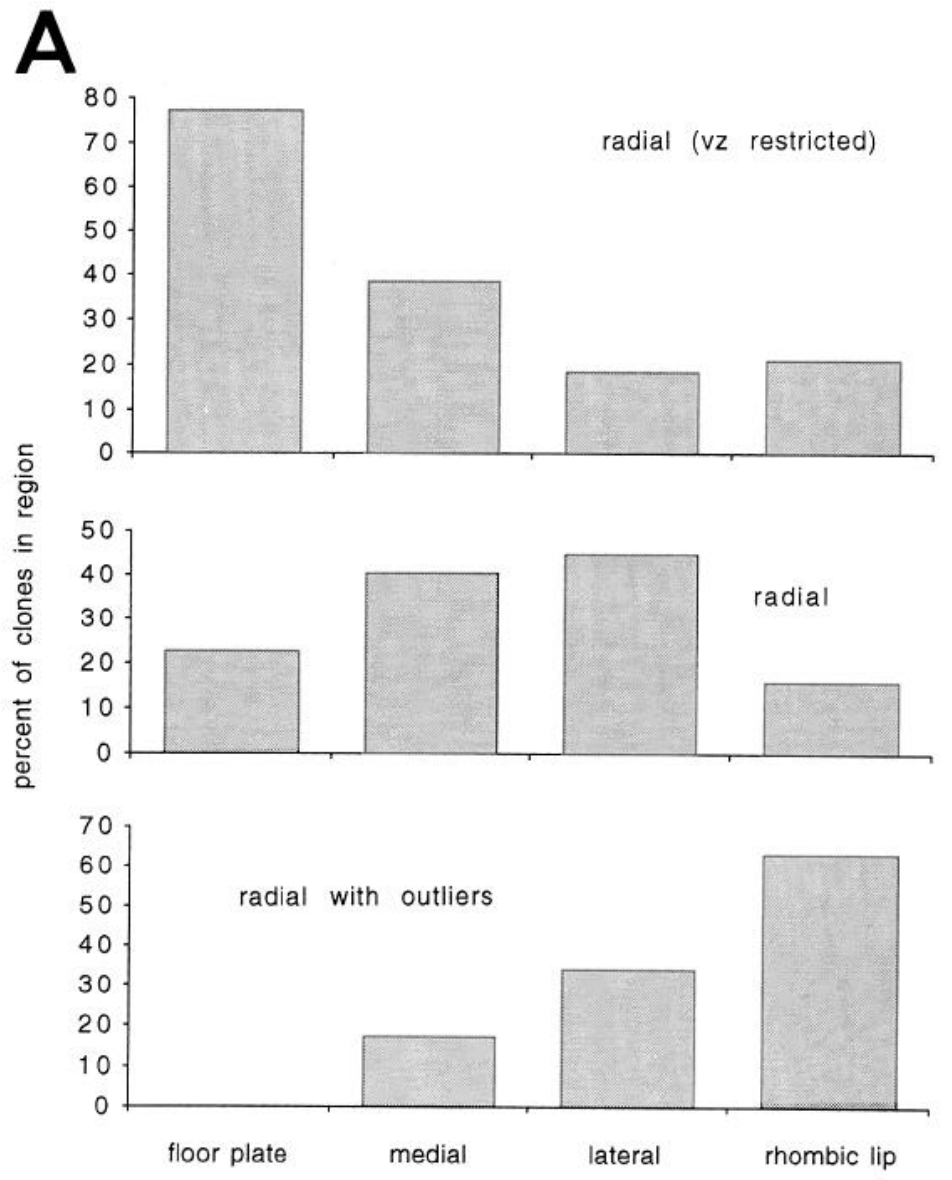

$B$

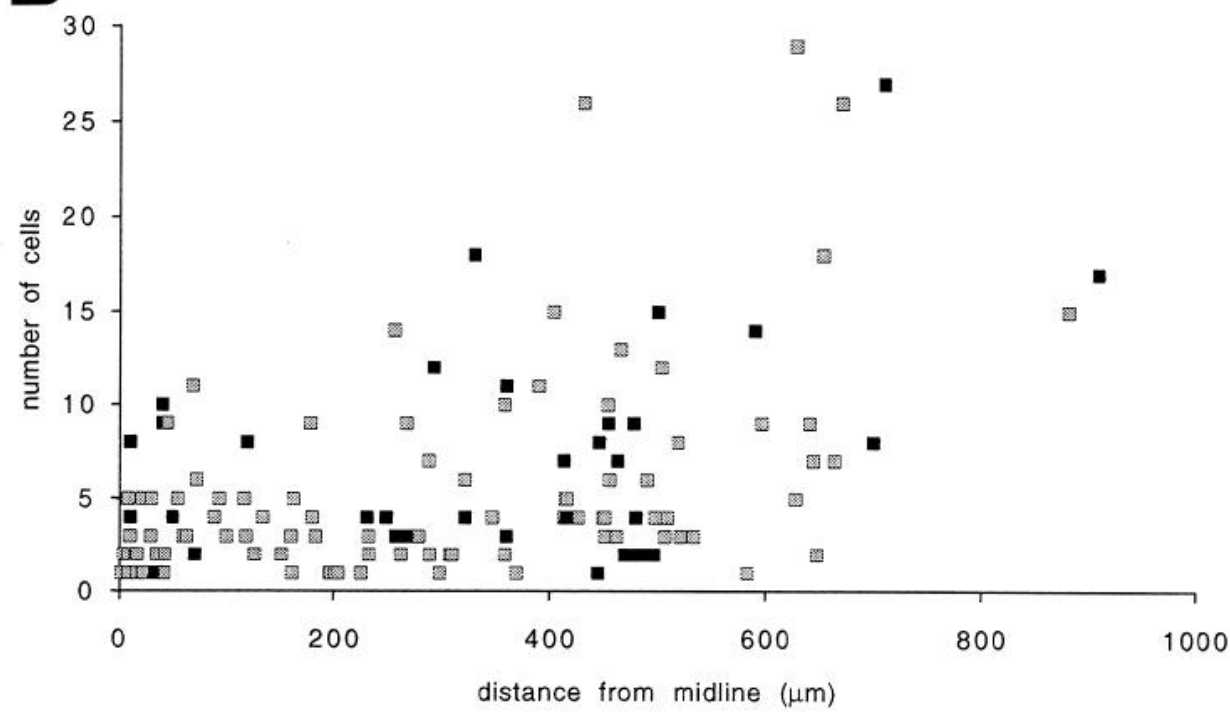

comprised longitudinally restricted, isolated sets that are likely to be homologous to the clones observed at stages 24-29. Four brainstems contained only a single set of labeled cells whose longitudinal extent was limited to less than about $150 \mu \mathrm{m}$; some such sets had a radial alignment and appeared similar to the radial clones at stages $24-29$. Three other brainstems contained two such sets of labeled cells that were isolated from each other and from any other labeled cells by at least $1 \mathrm{~mm}$ along the longitudinal axis (judging from the positions of cranial nerves, this distance probably corresponds to at least two rhombomeres). Taken together with the low apparent infection rate, the appearance of these eight isolated sets of labeled cells suggests that each arose from a single infection. They were therefore classified as putative clones, while the remainder of the labeled cells observed in stage 34-35 brainstems were excluded from analysis, either because they could not be resolved into spatially 
discrete sets, or because they were non-neural cells, like endothclial cells. The population of excluded cells corresponded numerically to approximately 26 putative clones.

The putative clones contained from 3 to 20 cells (mean = 11), and were distributed within the pons and the medulla (Fig. $3 B$ ). Many of the cells in the putative clones were well differentiated, and some could be identified as particular types of neurons on the basis of their morphology, size, and position (Fig. 5G,H). Indeed, several nuclei and neuron groups have completed their migration and are distinct by stage 34-35 (Harkmark, 1954; Peusner and Morest, 1977; Puelles, 1978; Moody and Heaton, 1981; Book and Morest, 1990; Tan and LeDouarin, 1991).

The putative clones exhibited a range of clone morphologies, including radial, radial with outliers, and nonradial (Fig. 8). Radial and radial with outlier putative clones $(n=4)$ resembled their stage 24-29 counterparts, except that the constituent cells were usually not contiguous (Fig. $8 C, D$ ). One radial putative clone was located in the floor plate, and consisted of approximately 10 closely packed cell bodies in the ventricular zone and an undetermined number of radial fibers extending to the pial surface. Some putative clones $(n=3)$ were "mixed," with a radial component proximal to the ventricular surface, and a nonradial component distal to the ventricular surface (Fig. $8 B$ ). The one nonradial putative clone contained cells that were dispersed throughout the transverse plane (Fig. $8 A$ ).

On histological grounds it was clear that while some cells in putative clones lay within specific brainstem nuclei, their cohorts could be distributed well beyond the nuclear boundaries (see Fig. $8 A$ caption). To provide another illustration of the extent to which dispersal could allocate cells to different functional neuron groups, we compared the putative clones to specific brainstem neuron groups defined in previously published retrograde tracing studies (Glover and Petursdottir, 1988). This showed that the putative clones had dispersed over regions expected to contain more than one functional type of neuron (Fig. $8 E)$.

\section{Discussion}

The brainstem has recently become a focus of attention among neuroembryologists because it develops from a series of segmental modules that define domains of lineage restriction and genetic expression. From this basic modular scheme arises an impressive diversity of neuronal cell phenotype and neural structure. To understand the processes that generate this diversity, we need more information about the proliferation and movement of cells in the brainstem neuroepithelium. Here we have used the retroviral lineage technique to follow clones of neural cells over a period of about 1 week, beginning during an early phase of proliferation and migration and concluding with the establishment of the major brainstem nuclei. This is the first description of clonal patterns of proliferation and migration in the brainstem over such an extended period of embryogenesis, and complements recent studies of cell lineage in the brainstem at earlier stages (Fraser et al., 1990).

\section{Potential sampling errors}

The retroviral lineage tracing technique, in its current form, precludes a labeling directed to individual identified progenitor cells. Thus, the definition of clones depends on criteria imposed after the clones have developed. To facilitate a secure identification of clones, we have limited the infection rate to very low levels, and applied a stringent set of criteria based on migratory barriers and cell contiguity. We are confident that the labeled cell clusters that meet these criteria are indeed clones. However, the exclusion of $38 \%$ ( 82 of 213 ) of the total number of cell clusters from analysis introduces the danger of misrepresenting the appearance and behavior of clones. Consequently, several potential errors in the analysis should be pointed out. One is an underestimate of clones containing few (one to four) cells. Another is an underestimate of nonradial clones and clones containing outlier cells, since when outliers could not be definitively assigned to one of several nearby clusters, all the outliers and clusters in question were excluded (see Fig. 1B). A third is an underestimate of large dispersed clones. Fraser et al. (1990) have observed considerable dispersal of clonally related cells within the plane of the neuroepithelium prior to stage 19. Many of the dispersed cells are probably also progenitors capable of generating clones of postmitotic daughters. If such dispersal is still occurring during the stages of our study, then we can imagine that a single infected progenitor cell could have generated two or more widely separated descendent progenitors within a single hemi-rhombomere. By our criteria, the separate subclones generated by such descendent progenitors would be indistinguishable from clones arising from separate infections.

These potential errors do not detract significantly from our conclusions. First, our aim has not been to provide an accurate census of the clone population; we allow that the smallest and largest classes of clones may be underrepresented. The excluded cells and cell clusters were distributed along the rostrocaudal and mediolateral axes in much the same way as the defined clones, so the validity of our conclusions is not limited to a particular region. Moreover, their inclusion has no appreciable effects on the size differences and mediolateral gradients we observed. Second, although the possibility of dispersed descendent progenitors is a natural extension of the observations made by Fraser et al. (1990), we have not attempted to reconstruct quantitatively the lineage sequence linking their observations to ours (indeed, attempts to label clones with the retrovirus at earlier stages were largely unsuccessful). By ignoring the possibility that separate clusters within the same hemi-rhombomere may be related subclones, we merely bias our observations toward a later stage in the lineage sequence, as if we had infected the descendent progenitor cells giving rise to each subclone, instead of their common progenitor.

\section{Clonal patterns of proliferation}

Neurogenesis in the brainstem begins at the neural plate stage (McConnell and Sechrist, 1980; Sechrist and Bronner-Fraser, 1991) and continues at least in some neuron groups through stages 24-29 (Rubel et al., 1976; Yurkewicz et al., 1981; Clarke, 1982a). We expected, therefore, to see an increase in the number of cells per clone with increasing time elapsed between injection and death, and a corresponding decrease in the number of cells per clone with successively later stages of injection. Both trends were observed. The most characteristic feature of the stage 2429 clones, however, is their variability in cell number; the distribution of clone size for clones with fixed injection and survival times can be just as large as for the entire clonc population.

The variability in number of cells per clone may result from events unrelated to proliferation, such as cell death or variability in the expression of the lac $Z$ gene. The only studies of naturally occurring cell death in the brainstem that we are aware of suggest that it is not appreciable until after day 9 (stage 35) in the auditory nuclei (Rubel et al., 1976) and the isthmo-optic nucleus 
Figure 8. Putative clones at stages 3435 maintain some of the morphological characteristics of stage 24-29 clones but are more widely dispersed. Representative examples of putative clones are illustrated in camera lucida drawings of single $200 \mu \mathrm{m}$ transverse sections ( $C$. $D)$ or composite drawings of two adjacent $200 \mu \mathrm{m}$ transverse sections $(A$, $B$ ). The location and spatial extent of these putative clones are shown in Figure $3 B$. $A$, A putative clone containing highly dispersed neurons. The four most dorsolateral neurons are all located within the auditory nuclei laminaris and magnocellularis. The nuclear outlines are not indicated because they change radically from the one to the other of the two sections from which this drawing was made. $B$, A putative clone that has a radial organization proximal to the ventricular surface but disperses distal to the ventricular surface. $C, A$ putative clone that has a radial organization, with a single outlier. The boxed region is shown at higher magnification in $D$. $E$, The dispersal of these putative clones covers several functionally distinct nuclei and neuron populations. This panel shows a composite camera lucida drawing of two $100 \mu \mathrm{m}$ sections, separated by $300 \mu \mathrm{m}$, from a stage 35 brainstem that received an injection of HRP unilaterally at cervical segment 1 . The sections bracket the region in which the putative clones in $A-D$ lie, and are superimposed on an outline of the most rostral section, which is about $200 \mu \mathrm{m}$ rostral to these putative clones. Each circle represents one reticulospinal neuron; each square represents one vestibulospinal neuron. Solid symbols represent ipsilaterally projecting neurons; open symbols represent contralaterally projecting neurons. $A B$, abducens nucleus; $N M$, nucleus magnocellularis; $N L$, nucleus laminaris. Scale bars: $A-C$ and $E, 500 \mu \mathrm{m} ; D, 100 \mu \mathrm{m}$.

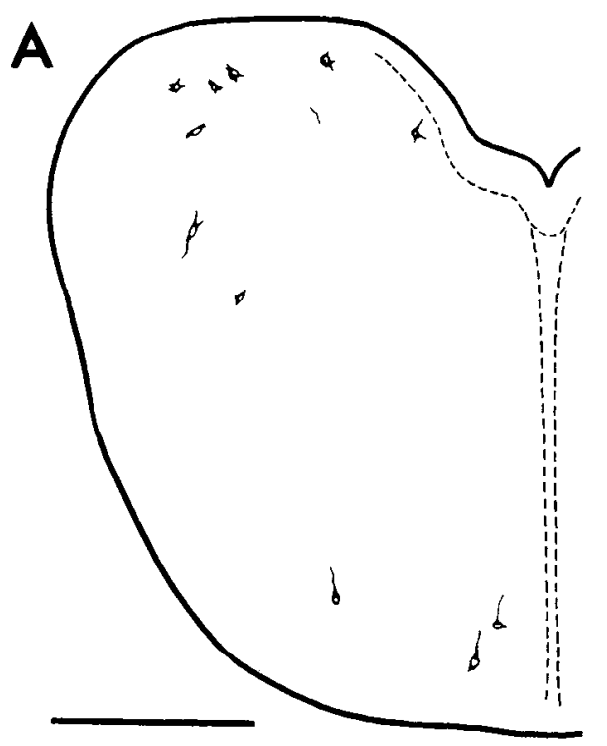

B
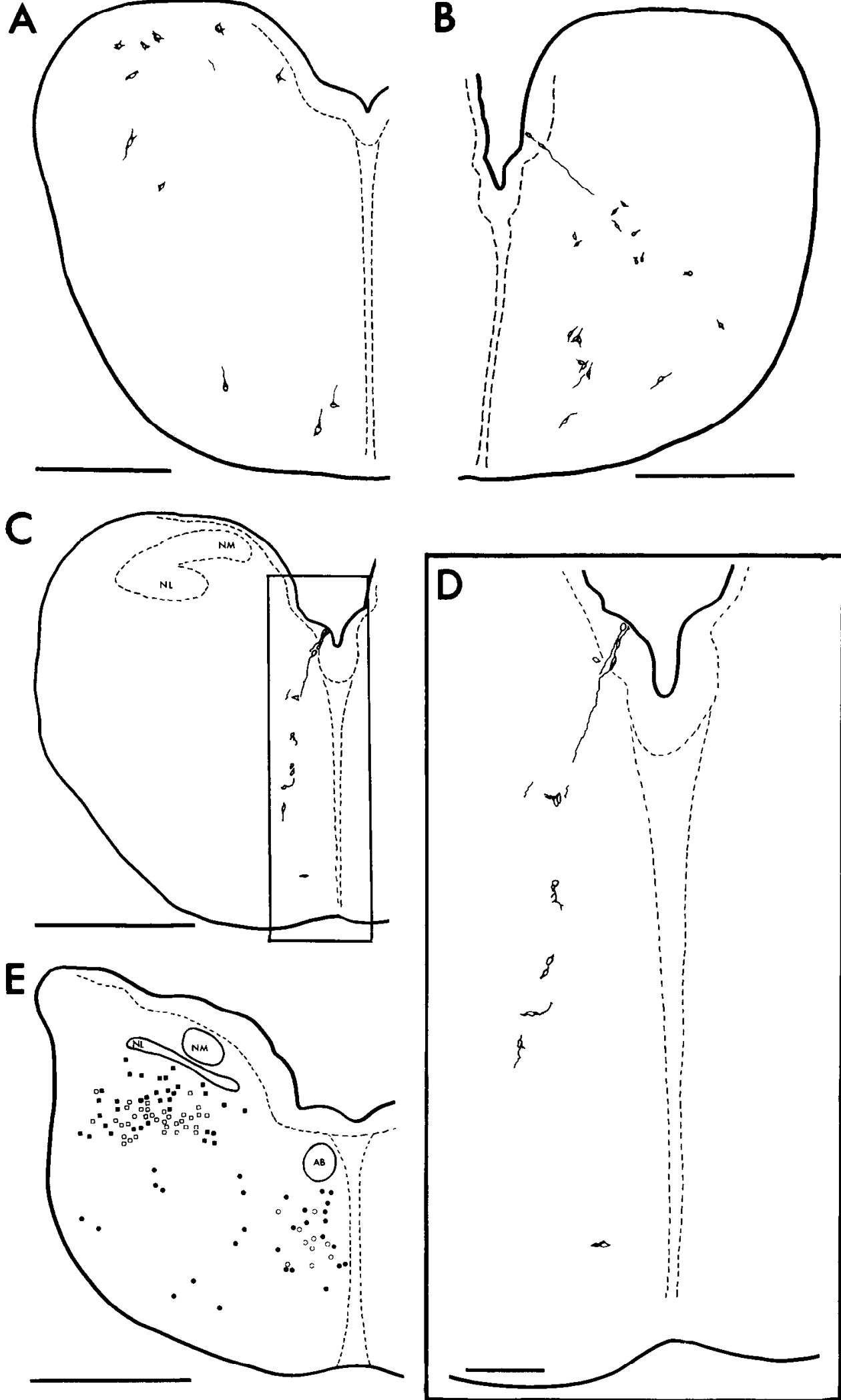

(Clarke, 1982b). In the retina, neither cell death nor variability in lac7 expression are prominent during neurogenesis, yet clone size is highly variable (Turner et al., 1990).

Despite the possibilities of cell death and variability in expression, it is instructive to examine how proliferation alone could produce the range of clone sizes reported here. It is gen- erally recognized that progenitor cells can divide either symmetrically or asymmetrically, providing the basis for two different modes of cell production. In the proliferative mode, division gives rise to two daughter cells, each of which retains proliferative capability. After $n$ cycles of proliferative division, the expected number of cells is therefore $2^{\text {n }}$. In the stem cell mode, 
one of the daughter cells is postmitotic while the other retains proliferative capability. After $n$ cycles of stem cell division, the expected number of cells is therefore $n+1$. Given the estimated $8 \mathrm{hr}$ cell cycle in the chicken embryo neural tube (Langman et al., 1966), the 46.5-88.5 hr of clone development represents about $6-11$ cycles. Thus, clones containing $7-12$ cells could have been generated purely by stem cell divisions, while clones containing $>12$ cells could have becn gencrated by some combination of proliferative and stem cell divisions. In this case, assuming a purely proliferative phase followed by a purely stem cell phase, the relationship between the number of proliferative $(p)$ and stem cell $(s)$ cycles is $2^{p}=x /(s+1)$, where $x$ is the number of cells in the clone, and $p+s$ is the total number of cycles. For example, the largest clone we observed contained 29 cells and was generated during $67 \mathrm{hr}$, or about eight cycles, and would therefore require two proliferative cycles.

For the entire sample of stage 24-29 clones, the average time of development was $61 \pm 10 \mathrm{hr}$, or about $7.6 \pm 1.3$ cell cycles. The average number of cell cycles is not very different from the average number of cells per clone $(5.7 \pm 5.5)$. Thus, barring any appreciable contribution from cell death or variability in $l a c Z$ expression, the progenitor population giving rise to these clones has effectively divided in the stem cell mode. Frederiksen and McKay (1988) have reported a similar observation for the rat embryo spinal cord, in which the number of progenitor cells approximates the number of neurons born on each day of development.

The arithmetic considerations above show how large clones can be generated by substituting proliferative divisions for stem cell divisions. Can variability in proliferative behavior also account for the majority of clones $(66 \%)$ that are smaller than the average of about six cells? One possibility is that some progenitors withdraw from the cell cycle during the period of study. A two-cell clone could be generated by a progenitor that undergoes a terminal mitosis immediately after being labeled, thereby forming only two labeled postmitotic daughters. A one-cell clone could be generated by infection during a terminal mitosis, assuming that the lac $Z$ construct is integrated into only one of the available host genomes (see Turner et al., 1990). Another possibility is that cell cycle time varies among progenitors. Large variations in cell cycle time are commonly observed in the genetically identical cells of cultured cell lines. Since estimates of cycle time in tissues are based on the behavior of the entire progenitor population, they provide little information about the source of variance about the mean. Small clones could have been generated by progenitors with cycle times longer than 8 hr. Likewise, large clones could have been generated by purely stem cell divisions if the cycle time was sufficiently short.

Neurogenesis in the chicken embryo spinal cord ceases by the end of the eighth day, about stage 34 (Fujita, 1964; Langman and Haden, 1970). Less is known about when neurogenesis ends in the brainstem, since it has been studied only in selected nuclei. Proliferation ceases in the locus coeruleus by stage 27 (Yurkewicz et al., 1981), and in the auditory nuclei magnocellularis and laminaris by $72 \mathrm{hr}$ (about stage 18) and $108 \mathrm{hr}$ (about stage 24), respectively (Rubel et al., 1976). With such limited information, it is difficult to predict the expected size of clones allowed to develop until stages 34-35. The putative clones at these stages contained on average about twice as many cells as the stage 24-29 clones, consistent with continued neuronal proliferation beyond stage 29 .

Gliogenesis continues after the cessation of neurogenesis in the chicken embryo (Fujita, 1964). Although glial cell differentiation can be followed from definite embryonic stages (see, e.g., Cameron-Curry et al., 1989), the onset of gliogenesis has not been defined in the brainstem. At present we cannot identify any of the cells in stage 24-29 clones as neurons or glia. Many of the cells in the stage 34-35 putative clones have morphologies characteristic of neurons, but the histochemical labeling is insufficient to render a judgement on all the cells.

\section{Clonal patterns of migration and dispersal}

In all regions of the CNS that have been studied thus far, there is an initial radial migration of postmitotic cells from the ventricular zone. In some regions this is followed by secondary tangential migrations that are temporally regular and spatially oriented (Gray et al., 1990). The relative predominance of radial and tangential modes may play a role in determining the characteristic structural and functional features of different regions.

The mediad migration of rhombic lip derivatives in the brainstem is a classic example of tangential migration (Harkmark, 1954), in which interest has been renewed recently (Bourrat and Sotelo, 1988; Ono and Kawamura, 1989; Book and Morest, 1990; Tan and LeDouarin, 1991). The rhombic lip is also the source of progenitors that give rise to cerebellar granule cells following a dorsolateral migration. Not surprisingly, clones originating from the rhombic lip exhibit considerable tangential migration. The existence of outlier cells in clones in other regions indicates, in addition, a less prominent tangential migration originating medial to the rhombic lip. Previously studied examples of tangential migration arising from the basal plate include the laterad migration of trigeminal motoneurons (Moody and Heaton, 1981) and the midline crossing by oculomotor neurons (Puelles, 1978).

What are the substrates for migration of postmitotic cells in the brainstem? As is commonly observed elsewhere in the CNS, radial migration appears to coincide with radial fibers that are R5 positive and vimentin positive and that extend to the pial surface. These may be radial glia or neuroepithelial progenitors (Drager, 1984; Bennett, 1987). We do not know the extent of the physical contact, if any, between these fibers and the migratory cells in the brainstem. In the optic tectum, such contact has been demonstrated at the ultrastructural level (Gray et al., 1990). Other potential substrates for radial migration in the brainstem are the axons of certain cranial nerves, and the leading processes of the migrating cells themselves (see Book and Morest, 1990).

The substrate for tangential migration in the brainstem has been ascribed to axons, with migration thought to be directed either by contact guidance (Bourrat and Sotelo, 1988; Ono and Kawamura, 1989; Rakic, 1990; Tan and LeDouarin, 1991), or by perikaryal translocation (reviewed in Book and Morest, 1990). We find that tangential migrants lie predominantly in lateral regions. The presence in lateral regions of R5- and vimentinpositive tangential fibers near the border between mantle and marginal zones implicates these also as potential substrates for tangential migration.

In the stage 34-35 putative clones, cells were often not contiguous, and this made it more difficult to deduce migratory patterns. Some putative clones maintained a high degree of radiality, while others had a radial component that dispersed distal to the ventricular zone. Still others exhibited much more dispersal than seen at stages 24-29. Indeed, most labeled cells at stages 34-35 were so scattered that they could not be resolved 
into separate sets, and were excluded from analysis on that ground. Thus, the extent to which clonal cohorts disperse by stages 34-35 may be significantly higher than that suggested by the sample of putative clones. Analysis of heterospecific chimeras has shown that some brainstem nuclei are likely to receive contributions from multiple progenitors, since they are derived from both alar and basal plates (Tan and LeDouarin, 1991). Our observations suggest the complementary mechanism, that single progenitors can contribute to multiple brainstem nuclei. This appears to be a common theme in the CNS, as clonal dispersal to functionally different neuron populations has been observed in the spinal cord (Leber et al., 1990), optic tectum (Gray et al., 1988), hippocampus (Grove et al., 1992), and neocortex (Walsh and Cepko, 1992).

\section{$A$ gradient along the mediolateral axis}

Regional differences in proliferative and migratory kinetics probably play an important role in shaping the developing neural tube. It has been suggested on the basis of histological appearances and counts of mitotic figures, respectively, that proliferation rates are highest at the rhombic lip (Harkmark, 1954) and lowest in the floor plate (van Straaten et al., 1988). Here we provide direct evidence for a mediolateral gradient of proliferative and migratory patterns, in which the prevalence of clones with the largest number of cells and the most tangential migration increases laterally.

The mediolateral increase in the density of radial with outlier clones is paralleled by a decrease in the density of radial clones with cell bodies restricted to the ventricular zone, while other radial clones have an intermediate distribution (Fig. $7 A$ ). A hypothetical temporal sequence in which these three clone classes represent successive stages in clone development would therefore suggest a general lateral to medial gradient of neurogenesis in the caudal brainstem. By contrast, birthdating studies have suggested a general mediolateral gradient in the mammalian brainstem (Taber Pierce, 1973), and a general ventrodorsal gradient in the spinal cord (Nornes and Das, 1974), which would be equivalent to a mediolateral gradient had the spinal cord been split open dorsally to approximate the appearance of the brainstem. Departure from the general trend has been noted in the spinal cord (Hollyday and Hamburger, 1977), and lateral to medial gradients have been reported for certain brainstem nuclei (Clarke et al., 1976; Altman and Bayer, 1980). Gradients deduced from birthdating can be misleading because they often are based on the ultimate location of postmitotic neurons as opposed to their sites of origin; indeed, some authors use the term "sequence of assembly" instead of "gradient of neurogenesis" (Hollyday and Hamburger, 1977). It is important to stress in this connection that statistical support for a sequential relationship among the three clone classes is at present weak, so a general lateral to medial gradient in the brainstem is by no means substantiated. It is also unlikely that there is an obligatory transition from the radial to the radial with outlier clone class, as radial clones can persist until stages 34-35 (see Fig. 8C,D).

The mediolateral increase in clone size that we have observed should not be confused with the gradients of neurogenesis suggested by birthdating studies. Nuclear labeling techniques can indicate where and when proliferation occurs, but cannot provide information about the proliferative behavior of individual progenitors within a large labeled progenitor population. Our observations are insufficient to define a spatiotemporal sequence of proliferation, but do indicate differences among individual progenitors during a defined period of proliferation. We suggest on the basis of these observations the testable hypothesis that the three clone classes do not represent transitional forms, but rather distinct subpopulations that differ in proliferative kinetics and migratory behavior throughout their genesis.

Little is known about the control of proliferation in the neuroepithelium. Growth factors can affect the rate of proliferation of neuronal progenitor ccll lincs in culture (Cattaneo and McKay, 1990). It is not unreasonable to imagine that the notochord and floor plate, midline structures that are known to polarize cell determination patterns in the neural tube (see Glover, 1991, for review), could effect a mediolateral gradient of growth factors and thereby of proliferation. Indeed, mitotic activity can be reduced in lateral neuroepithelium exposed to an ectopic notochord (van Straaten et al., 1988), suggesting that the notochord exerts a direct distance-dependent inhibition of proliferation that is normally greatest at the floor plate. If all progenitors have equivalent proliferative potential, then such a mechanism would generate a continuous function relating clone size to mediolateral position. Alternatively, progenitors might not be equivalent, but rather be determined to generate intrinsically different clone sizes. In this case, a gradient of some signal that induces the progenitors with greater proliferative potential would provide a mechanism for differentially regulating proliferation along the mediolateral axis.

The possibility of intrinsic differences among progenitors is also relevant in considering the migratory behavior of clones. If all clones are initially equivalent, then the medial to lateral increase in the number of radial with outlier clones could arise from a gradient of cues that either promote tangential migration or disrupt radial migration. There is evidence for the latter in the rhombic lip region, where the radial pattern of R5-positive fibers (present study) and neuroepithelial cell processes (Book and Morest, 1990) is disrupted. Alternatively, it could arise on an even distribution of mixed radial and tangential migratory cues if there is a gradient of induction of progenitors whose progeny specifically recognize the tangential cues.

\section{From early to late lineages}

The clones observed by Fraser et al. (1990) were generated over 24-48 hr (from stages 6-12 to stages 18-19, hereafter defined as "early") and contained from 4 to 64 cells (mean $=16.3$ ). Clonal cohorts dispersed rostrocaudally and mediolaterally and intermingled with unlabeled cells in a ratio ranging from $1: 3$ to $1: 30$ (mean, $1: 10$ ). In contrast, the clones that we observed were generated over 46.5-88.5 hr (from stages 13-17 to stages 2429 , hercaftcr defined as "late") and contained from 1 to 29 cells (mean $=5.6)$. Clonal cohorts in "late" clones exhibited little if any rostrocaudal dispersal, and limited mediolateral (tangential) dispersal. Indeed, most were restricted to a narrow radial array. Clearly the "early" and "late" clones differ in their kinetics of proliferation and dispersal. It is reasonable to assume that the "late" clones represent subclones of the "early" clones. One interpretation of the transition in proliferative and dispersive behavior is therefore as follows. At early stages progenitor cells exhibit primarily proliferative divisions, generating large clones of descendent progenitor cells. These descendent progenitor cells are free to mix and disperse within the ventricular zone, with the exception that they cannot cross rhombomere boundaries. At later stages the descendent progenitor cells undergo primarily stem cell divisions to generate relatively small, rostrocaudally restricted clones of postmitotic cells. The postmitotic cells ini- 

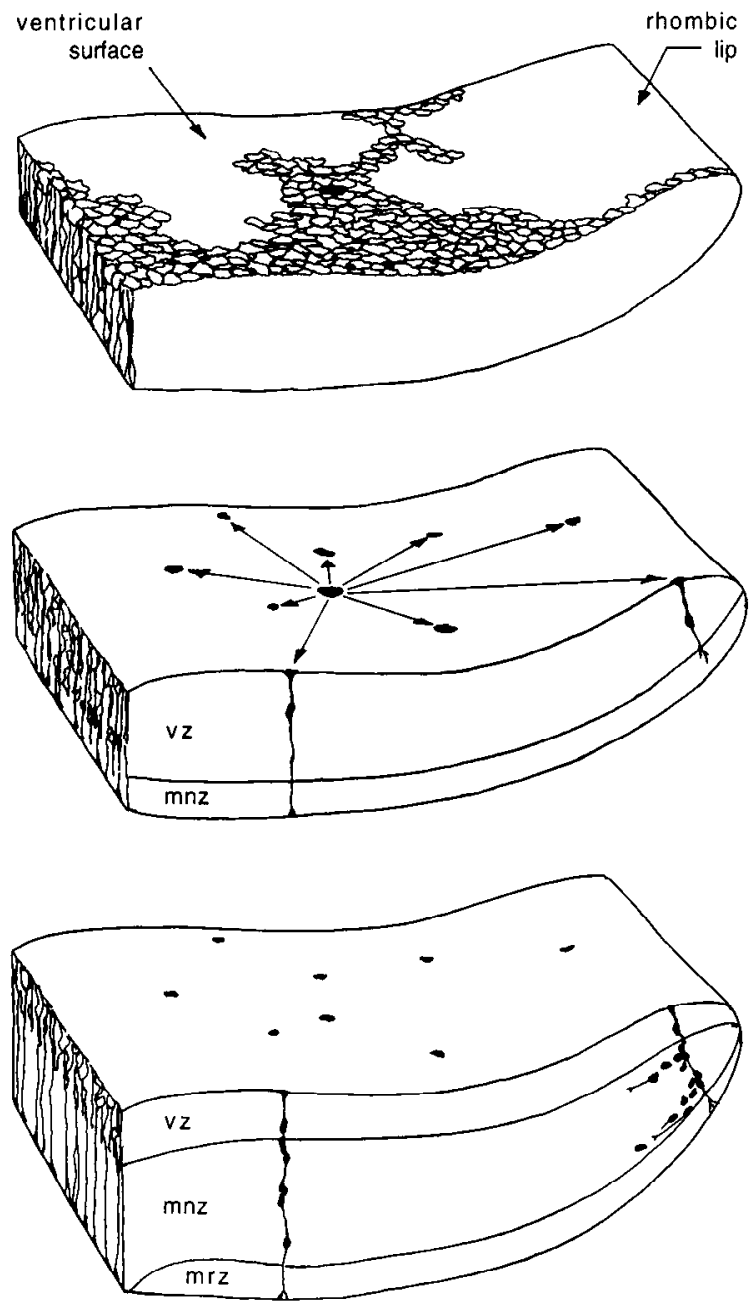

Figure 9. A model of proliferation and migration in the brainstem consistent with the results reported here and by Fraser et al. (1990). This model is depicted in a single hemi-rhombomere (floor plate not shown) at sequential stages. At early stages, prior to the birth of most neurons ( $t o p)$ the brainstem neuroectoderm is a simple epithelium composed primarily of primitive neuroepithelial cells. One of these, near the middle of the hemi-rhombomere, has been labeled. By a later stage (middle), the labeled neuroepithelial cell has proliferated to form a clone of descendent progenitors that have dispersed within the plane of the ventricular zone. At this stage a few neurons have been born and have migrated out of the ventricular zone $(v z)$ to form the mantle zone $(m n z)$. At subsequent stages (bottom), each of the labeled descendent progenitors generates a clone of progeny that migrates into the mantle zone. Migration is primarily radial along most of the mediolateral axis. The number of cells per clone and the degree of tangential migration both increase from medial to lateral. $m r z$, marginal zone.

tially migrate radially from the ventricular zone, but then some of them take up a secondary tangential migration that leads to dispersal within the mantle zone. Such tangential migration is particularly prominent in the lateral regions. Figure 9 presents a visual model of this sequence of events. Similar models have been proposed for the optic tectum and spinal cord of the chicken embryo (Gray et al., 1990).

\section{Summary}

Progenitor cells in the brainstem vary in proliferative kinetics, generate clones that follow different migratory patterns, and probably contribute descendants to disparate brainstem nuclei. Thus, this population of progenitors shares many of the char- acteristics of progenitor populations in other brain regions. Here we have described an additional feature of particular interest for understanding the construction of the brainstem: a systematic correlation between proliferation, migratory pattern, and mediolateral position. This correlation has two interesting implications. First, it demonstrates that the regulation of proliferation and migration is spatially complex. Mediolateral variation in proliferation may be as important a determinant of neural structure as the longitudinal variation that generates size differences among brain regions. Mediolateral variation in migratory pattern underscores the pivotal role of the rhombic lip as a source of dispersive clones that intermix different lineages. Second, it suggests the possibility that brainstem progenitors are not equivalent, and that one means of generating spatial differences in proliferation and migration is to regulate the relative proportions of different types of progenitors. We propose observing labeled clones as they develop in situ as an initial step toward testing this hypothesis.

\section{References}

Adams JC (1981) Heavy metal intensification of DAB-based HRPreaction product. J Histochem Cytochem 29:775.

Altman J, Bayer SA (1980) Development of the brain stem in the rat. III. Thymidine-radiographic study of the time of origin of neurons of the vestibular and auditory nuclei of the upper medulla. J Comp Neurol 194:877-904.

Austin AP, Cepko CL (1990) Cellular migration patterns in the developing mouse cerebral cortex. Development 110:713-732.

Bennett GS (1987) Changes in intermediate filament composition during neurogenesis. Curr Top Dev Biol 21:151-183.

Book K, Morest DK (1990) Migration of neuroblasts by perikaryal translocation: role of cellular elongation and axonal outgrowth in the acoustic nuclei of the chick embryo medulla. J Comp Neurol 297: $55-76$.

Bourrat F, Sotelo C (1988) Migratory pathways and neuritic differentiation of inferior olivary neurons in the rat embryo. Axonal tracing study using the in vitro slab technique. Dev Brain Res 39:19-37.

Cameron-Curry P, Dulac C, LeDouarin NM (1989) Expression of the SMP antigen by oligodendrocytes in the developing avian central nervous system. Development 107:825-833.

Cattaneo E, McKay R (1990) Proliferation and differentiation of neuronal stem cells regulated by nerve growth factor. Nature 347:762765.

Clarke PGH (1982a) The generation and migration of the chick's isthmic complex. J Comp Neurol 207:208-222.

Clarke PGH (1982b) The genuineness of isthmo-optic neuronal death in chick embryos. Anat Embryol (Berl) 165:389-404.

Clarke PGH, Rogers LA, Cowan WM (1976) The time of origin and the pattern of survival of neurons in the isthmo-optic nucleus of the chick. J Comp Neurol 167:125-142.

Drager UJ (1984) Antibodies against filamentous components in discrete cell types of the mouse retina. J Neurosci 4:2025-2042.

Fraser S, Keynes R, Lumsden A (1990) Segmentation in the chick embryo hindbrain is defined by cell lineage restrictions. Nature 344: 431-434.

Frederiksen K, McKay RDG (1988) Proliferation and differentiation of rat neuroepithelial precursor cells in vivo. J Neurosci 8:1144-1151.

Fujita S (1964) Analysis of neuron differentiation in the central nervous system by tritiated thymidine autoradiography. J Comp Neurol 122:311-327.

Galileo DS, Gray GE, Owens GC, Majors J, Sanes JR (1990) Neurons and glia arise from a common progenitor in chick optic tectum: demonstration with two retroviruses and cell type-specific antibodies. Proc Natl Acad Sci USA 87:458-462.

Glover JC (1991) Inductive events in the neural tube. Trends Neurosci 14:424-427.

Glover JC, Petursdottir G (1988) Pathway specificity of reticulospinal and vestibulospinal projections in the 11-day chicken embryo. J Comp Neurol 270:25-38.

Gray GE, Glover JC, Majors J, Sanes JR (1988) Radial arrangement of clonally related cells in the chicken optic tectum: lineage analysis 
with a recombinant retrovirus. Proc Natl Acad Sci USA 85:73567360 .

Gray GE, Leber SM, Sanes JR (1990) Migratory patterns of clonally related cells in the developing central nervous system. Experientia 46: 929-940.

Griffith CM, Sanders EJ (1991) Differentiation of the chick embryo floor plate. Anat Embryol (Berl) 184:159-169.

Grove EA, Kirkwood TBL, Price J (1992) Neuronal precursor cells in the rat hippocampal formation contribute to more than one cytoarchitectonic area. Neuron 8:217-229.

Hamburger V, Hamilton HL (1951) A series of normal stages in the development of the chick embryo. J Morphol 88:49-92.

Harkmark W (1954) Cell migrations from the rhombic lip to the inferior olive, the nucleus raphe and the pons. A morphological and experimental investigation on chick embryos. J Comp Neurol 100: 115-210.

Hemond SG, Glover JC (1991) Clonal patterns of neuron proliferation and dispersal in the brain stem of the chicken embryo. Soc Neurosci Abstr 17:1478.

Hogg RV, Craig AT (1970) Introduction to mathematical statistics, 3d ed. New York: Macmillan.

Hollyday M, Hamburger V (1977) An autoradiographic study of the formation of the lateral motor column in the chick embryo. Brain Res 132:197-208.

Holt C, Bertsch TW, Ellis HM, Harris WA (1988) Cellular determination in the Xenopus retina is independent of lineage and birth date. Neuron 1:15-26.

Langman J, Haden CC (1970) Formation and migration of neuroblasts in the spinal cord of the chick embryo. J Comp Neurol 138:419-432

Langman J, Guerrant R, Freeman B (1966) Behavior of neuroepithelial cells during closure of the neural tube. J Comp Neurol 127:399412.

Leber SM, Breedlove SM, Sanes JR (1990) Lineage, arrangement, and death of clonally related motoneurons in chick spinal cord. J Neurosci 10:2451-2462.

Lumsden A (1990) The cellular basis of segmentation in the developing hindbrain. Trends Neurosci 13:329-335.

Luskin MB, Pearlman AL, Sanes JR (1988) Cell lineage in the cerebral cortex of the mouse studied in vivo and in vitro with a recombinant retrovirus. Neuron 1:635-647.

McConnell JA, Sechrist JW (1980) Identification of early neurons in the brainstem and spinal cord: I. An autoradiographic study in the chick. J Comp Neurol 192:769-783.

McKanna JA, Cohen S (1989) The EGF receptor kinase substrate p35 in the floor plate of the embryonic rat CNS. Science 243:1477-1479.

Moody SA, Heaton MB (1981) Morphology of migrating trigeminal motor neuroblasts as revealed by horseradish peroxidase retrograde labeling techniques. Neuroscience 6:1707-1723.

Nornes HO, Das GD (1974) Temporal pattern of neurogenesis in spinal cord of rat. I. An autoradiographic study-time and sites of origin and migration and settling patterns of neuroblasts. Brain Res 73:121-138.

Ono K, Kawamura K (1989) Migration of immature neurons along tangentially oriented fibers in the subpial part of the fetal mouse medulla oblongata. Exp Brain Res 78:290-300.

Parnevelas JG, Barfield JA, Franke E, Luskin MB (1992) Separate progenitor cells give rise to pyramidal and nonpyramidal neurons in the rat telencephalon. Cereb Cortex 1:463-468.

Peusner KD, Morest DK (1977) A morphological study of neurogenesis in the nucleus vestibularis tangentialis of the chick embryo. Neuroscience 2:209-227.
Price J, Thurlow L (1988) Cell lineage in the rat cerebral cortex: a study using retroviral-mediated gene transfer. Development 104:473482.

Puelles L (1978) A Golgi-study of oculomotor neuroblasts migrating across the midline in chick embryos. Anat Embryol (Berl) 152:205215.

Rakic P (1990) Principles of neural cell migration. Experientia 46: 882-891.

Rubel EW, Smith DJ, Miller LC (1976) Organization and development of brain stem auditory nuclei of the chicken: ontogeny of n. magnocellularis and $n$. laminaris. J Comp Neurol 166:469-490.

Sanes JR, Rubinstein JLR, Nicolas JF (1986) Use of a recombinant retrovirus to study post-implantation cell lineage in mouse embryos. EMBO J 12:3133-3142.

Sechrist J, Bronner-Fraser M (1991) Birth and differentiation of reticular neurons in the chick hindbrain: ontogeny of the first neuronal population. Neuron 7:947-963.

Stern CD, Jacques KF, Lim TM, Fraser SE, Keynes RJ (1991) Segmental lineage restrictions in the chick embryo spinal cord depend on the adjacent somites. Development 113:239-244.

Straus W (1972) Phenylhydrazine as inhibitor of horseradish peroxidase for use in immunoperoxidase procedures. J Histochem Cytochem 20:949-951.

Taber Pierce E (1973) Time of origin of neurons in the brainstem of the mouse. Prog Brain Res 40:53-65.

Tan K, LeDouarin NM (1991) Development of the nuclei and cell migration in the medulla oblongata: application of the quail-chick chimera system. Anat Embryol (Berl) 183:321-343.

Tessier-Lavigne M, Placzek M, Lumsden AGS, Dodd J, Jessell TM (1988) Chemotropic guidance of developing axons in the mammalian central nervous system. Nature 336:775-778.

Turner DL, Cepko CL (1987) A common progenitor for neurons and glia persists in rat retina late in development. Nature 328:131-136.

Turner DL, Snyder EY, Cepko CL (1990) Lineage-independent determination of cell type in the embryonic mouse retina. Neuron 4:833845.

Vaage $S$ (1969) The segmentation of the primitive neural tube in chick embryos (Gallus domesticus). Adv Anat Embryol Cell Biol 41:1-88.

Vanselow J, Thanos S, Godement P, Henke-Fahle S, Bonhoeffer F (1989) Spatial arrangement of radial glia and ingrowing retinal axons in the chick optic tectum during development. Dev Brain Res 45:15-27.

van Straaten HWM, Hekking JWM, Wiertz-Hoessels EJLM, Thors F, Drukker J (1988) Effect of the notochord on the differentiation of a floor plate area in the neural tube of the chick embryo. Anat Embryol (Berl) 177:317-324.

Wagner M, Thaller C, Jessell T, Eichele G (1990) Polarizing activity and retinoid synthesis in the floor plate of the neural tube. Nature 345:819-822.

Walsh C, Cepko CL (1988) Clonally related cortical cells show several migration patterns. Science 241:1342-1345.

Walsh C, Cepko CL (1992) Widespread dispersion of neuronal clones across functional regions of the cerebral cortex. Science 255:434-440.

Wetts R, Fraser SE (1988) Multipotent precursors can give rise to all major cell types of the frog retina. Science 239:1142-1145.

Yurkewicz L, Lauder JM, Marchi M, Giacobini E (1981) ${ }^{3} \mathrm{H}$-thymidine long survival autoradiography as a method for dating the time of neuronal origin in the chick embryo: the locus coeruleus and cerebellar Purkinje cells. J Comp Neurol 203:257-267. 